\title{
1 Loss of $\mathrm{ZnT8}$ function protects against diabetes by enhanced insulin
}

\section{secretion}

Om Prakash Dwivedi ${ }^{1 \#}$, Mikko Lehtovirta ${ }^{1 \#}$, Benoit Hastoy ${ }^{2 \#}$, Vikash Chandra $^{3}$, Sandra Kleiner ${ }^{4}$, Deepak Jain ${ }^{5}$, Ann-Marie Richard ${ }^{6}$, Nicola L. Beer ${ }^{2}$, Nicole A. J. Krentz ${ }^{7}$, Rashmi B. Prasad ${ }^{8}$, Ola Hansson $^{1,8}$, Emma Ahlqvist ${ }^{8}$, Ulrika Krus ${ }^{8}$, Isabella Artner ${ }^{8}$, Daniel Gomez ${ }^{4}$, Aris Baras ${ }^{4}$, Fernando Abaitua $^{7}$, Benoite Champon ${ }^{7}$, Anthony J Payne ${ }^{7}$, Daniela Moralli ${ }^{7}$, Soren K. Thomsen ${ }^{2}$, Philipp Kramer $^{7}$, Ioannis Spiliotis ${ }^{2}$, Reshma Ramracheya ${ }^{2}$, Pauline Chabosseau ${ }^{9}$, Andria Theodoulou ${ }^{9}$, Rebecca Cheung ${ }^{9}$, Martijn van de Bunt ${ }^{2,7}$, Jason Flannick ${ }^{10,11}$, Maddalena Trombetta ${ }^{12}$, Enzo Bonora $^{12}$, Claes B. Wolheim ${ }^{8}$, Leena Sarelin ${ }^{13}$, Riccardo C. Bonadonna ${ }^{14}$, Patrik Rorsman ${ }^{2}$, Guy A Rutter $^{9}$, Benjamin Davies ${ }^{7}$, Julia Brosnan ${ }^{6}$, Mark I. McCarthy' ${ }^{2,7,15}$, Timo Otonkoski ${ }^{3}$, Jens O. Lagerstedt $^{5}$, Jesper Gromada ${ }^{4}$, Anna L. Gloyn ${ }^{2,7,15^{*}}$, Tiinamaija Tuomi ${ }^{1,13,16}$ and Leif Groop ${ }^{1,8^{*}}$

1. Institute for Molecular Medicine Finland (FIMM), Helsinki University, Helsinki, Finland.

2. Oxford Centre for Diabetes Endocrinology \& Metabolism, University of Oxford, UK.

3. Research Programs Unit, Molecular Neurology and Biomedicum Stem Cell Centre, Faculty of Medicine, University of Helsinki, Finland.

4. Regeneron Pharmaceuticals, Tarrytown, New York, USA.

5. Department of Experimental Medical Science, Lund University, 221 84, Lund, Sweden.

6. Pfizer Inc, Cambridge, MA, United States of America.

7. Wellcome Centre for Human Genetics, University of Oxford, UK.

8. Lund University Diabetes Centre, Department of Clinical Sciences, Lund University, Skåne University Hospital, SE-20502 Malmö, Sweden.

9. Section of Cell Biology, Department of Medicine, Imperial College London, Imperial Centre for Translational and Experimental Medicine, Hammersmith, Hospital, Du Cane Road, London, W12 0NN, UK.

10. Department of Molecular Biology, Massachusetts General Hospital, Boston, Massachusetts, USA.

11. Program in Medical and Population Genetics, Broad Institute, Cambridge, Massachusetts, USA. 
12. Department of Medicine, University of Verona and Azienda Ospedaliera Universitaria Integrata of Verona, Verona, Italy

13. Folkhälsan Research Center, Helsinki, Finland.

14. The Azienda Ospedaliera Universitaria of Parma, 43125 Parma, Italy. Obesity, University of Helsinki, Helsinki, Finland.

\# These authors contributed equally to the study

*Correspondence: Leif Groop, Institute for Molecular Medicine Finland (FIMM), Helsinki University. Leif. 


\section{Abstract}

A rare loss-of-function variant p.Arg138* in SLC30A8 encoding the zinc transporter 8 (ZnT8)

71 enriched in Western Finland protects against type 2 diabetes (T2D). We recruited relatives of the identified carriers and showed that protection was associated with better insulin secretion due to enhanced glucose responsiveness and proinsulin conversion, especially compared with individuals matched for the genotype of a common T2D risk variant in SLC30A8, p.Arg325. In genome-edited human IPS-derived $\beta$-like cells, we establish that the p.Arg138* variant results in reduced SLC30A8 expression due to haploinsufficiency. In human $\beta$-cells loss of SLC30A8 leads to increased glucose responsiveness and reduced $\mathrm{K}_{\mathrm{ATP}}$ channel function, which was also seen in isolated islets from carriers of the T2D-protective allele p.Trp325. These data position ZnT8 as an appealing target for treatment aiming at maintaining insulin secretion capacity in T2D. 


\section{Introduction}

Zinc transporters (ZnTs) regulate the passage of zinc across biological membranes out of the cytosol, while Zrt/Irt-like proteins transport zinc into the cytosol ${ }^{1}$. ZnT8, encoded by SLC30A8, is highly expressed in membranes of insulin granules in pancreatic $\beta$-cells, where it transports zinc ions for crystallization and storage of insulin ${ }^{2}$. We have described a loss-of-Function (LoF) variant p.Arg138* (rs200185429, c.412C>T) in the SLC30A8 gene, which conferred 53\% protection against $\mathrm{T}_{2} \mathrm{D}^{3}$. This variant was extremely rare $(0.02 \%)$ in most European countries but more common $(>0.2 \%)$ in Western Finland ${ }^{3}$. We also reported a protective frameshift variant p.Lys34Serfs*50 conferring $83 \%$ protection against T2D in Iceland. A recent $(>44 \mathrm{~K})$ exome sequencing study reported $>30$ alleles in $S L C 30 A 8$ reducing the risk of T2D, confirming it as a robust target for T2D protection ${ }^{4}$. Further, the $S L C 30 A 8$ gene also harbors a common variant (rs13266634, c.973T>A) p.Trp325Arg in the C-terminal domain ${ }^{5}$. While the major p.Arg325 allele ( $>70 \%$ of the population) confers increased risk for T2D, the minor p.Trp325 allele is protective . $^{6}$

The mechanisms by which reduced activity of ZnT8 protect against T2D are largely unknown. Several attempts have been made to study loss of Slc30a8 function in rodent models, but the results have been inconclusive: knock-out of Slc30a8 led to either glucose intolerance or had no effect in mice $^{7,8,9}$, while over-expression improved glucose tolerance without effect on insulin secretion ${ }^{10}$. In a mouse model harbouring the equivalent of the human p.Arg $138^{*}$ variant we were unable to detect any ZnT8 protein and observed no effect on glucose ${ }^{11}$. These rodent in vitro and in vivo experiments present a complex picture which might not recapitulate the T2D protective effects by SLC30A8 LoF mutations in humans. We therefore performed detailed metabolic studies in human carriers of the LoF variant (p.Arg138*) recruited on the basis of their genotype, performed comprehensive functional studies in human $\beta$-cell models and compared with the mouse model carrying the human p.Arg138*-SLC30A8 mutation. 


\section{Results}

108

\section{Recruitment by genotype}

Given the enrichment of the p.Arg138*-SLC30A8 variant in Western Finland, we genotyped $>14,000$ individuals from the Botnia Study ${ }^{12}$ for the SLC 30A8 p.Arg138* mutation and the common p.Trp325Arg variant (Fig. 1). None of the p.Arg138* mutation carriers was homozygous for the protective common variant, p.Trp325 and p.Arg138* segregated with p.Arg325 in the families (Supplementary Fig. 1). Thus, we present the data in three different ways: 1) p.Arg138*vs. all p.Arg138Arg, 2) p.Arg138* vs. p.Arg138Arg having at least one p.Arg325 allele (p.Trp325Arg or p.Arg325Arg), and 3) p.Arg325 (p.Trp325Arg or p.Arg325Arg) vs. p.Trp325Trp on a background of p.Arg138Arg. We included 79 p.Arg138* carriers and 103 non-carriers. Of them, 54 p.Arg138* and their 47 relatives with p.Arg138Arg participated in a test meal (Fig. 1 and Supplementary Table 1). In addition, 35 p.Arg 138* and 8141 p.Arg138Arg had previously undergone an oral glucose tolerance test (OGTT, Fig. 1 and Supplementary Table 2).

Replicating our previous findings ${ }^{3}$, carriers of p.Arg $138^{*}$ had reduced risk of T2D $(\mathrm{OR}=0.40$, $\mathrm{P}=0.003)$ in analysis of total $4564 \mathrm{~T} 2 \mathrm{D}$ subjects (13 p.Arg138* carriers ) and 8183 non-diabetic (55 p.Arg 138* carriers) individuals. Additionally, non-diabetic p.Arg138* carriers have lower fasting glucose concentrations $(\mathrm{P}=0.033)$ than $\mathrm{p} . \mathrm{Arg} 138 \mathrm{Arg}$. There were no significant differences in plasma zinc concentrations measured during test meal or OGTT (data not shown).

Comparison of p.Arg138*vs.p.Arg138Arg: The p.Arg138* carriers have lower blood glucose levels during test meal specifically during the first 40 minutes $(\mathrm{P}=0.02)$ and better corrected insulin response (CIR) (at $20 \mathrm{~min}, \mathrm{p}=0.046)$ than non-carriers (Fig. 2a and Supplementary Tables 3). Similarly, the carriers had better insulin response to OGTT (Fig 3b-c, left panel), especially the early incremental insulin response $(\mathrm{p}=0.008)$ and insulin/glucose ratio (at $30 \mathrm{~min}, \mathrm{p}=0.002$, 
Supplementary Tables 4). Of note, the p.Arg138* carriers had significantly lower proinsulin/C-

131 peptide (20 min: $\mathrm{P}=0.041 ; 40 \mathrm{~min}: \mathrm{P}=0.043)$ and proinsulin/insulin (20 min: $\mathrm{P}=0.006)$ ratios during

132 test meal suggesting effects on proinsulin conversion (Fig. 2d-e). No differences were seen in

133 glucagon, GLP-1 or free fatty acids concentrations during test meal (Supplementary Fig. 2c-e).

134 Neither model-based insulin clearance index nor the ratio of insulin and C-peptide areas under the 135 curve during test meal differed between p.Arg138* and p.Arg138Arg, making changes in insulin 136 clearance ${ }^{13}$ unlikely (Supplementary Fig. 2f-g).

137 Comparison of p.Arg138*vs.p.Arg138Arg-p.Arg325: The above differences were magnified when

138 we restricted the p.Arg138Arg group to carriers of the common risk variant p.Arg325 (middle panel 139 of Fig. 2). The early phase (0-40 min) insulin ( $p=0.026)$, insulin/glucose ratio $(p=0.004)$ and CIR $140 \quad(\mathrm{p}=0.004 ; 20 \mathrm{~min}$, Supplementary Table 3) were all greater in p.Arg 138* carriers compared with 141 those having p.Arg138Arg on a background of p.Arg325. Both the proinsulin/C-peptide (20 min: $\mathrm{P}=0.027,40 \mathrm{~min}: \mathrm{P}=0.044)$ and proinsulin/insulin ratios (20 min: $\mathrm{P}=0.003)$ were reduced in p.Arg 138* carriers (middle panel of Fig. 2d-e).

Comparison of p.Trp325Trp vs. p.Arg325: The effect of p.Trp325Trp genotype on glucose and insulin response mimicked the effects of p.Arg138* with pronounced early (20 min) insulin $(\mathrm{p}=0.035)$ and $\mathrm{C}$-peptide $(\mathrm{p}=0.025)$ responses during test meal (right panel of Fig. $2 \mathrm{~b}-\mathrm{c}$ and Supplementary Fig. 2a), as well as increased insulin secretion (30 min insulin, $30 \mathrm{~min}$ insulin/glucose, incremental insulin , $\mathrm{P} \leq 0.003$ ) and lower fasting and 120 minute proinsulin 149 ( $\mathrm{p}=0.006$ and $\mathrm{p}=0.039$, respectively) concentration during OGTT in $\mathrm{p} . \operatorname{Trp} 325$ carriers 150 (Supplementary Table 4, right panel of Fig. 3b-c). Moreover, p.Trp325Trp carriers undergoing 151 intravenous glucose tolerance tests (IVGTT) showed a pronounced $(\mathrm{p}=0.003)$ early incremental 152 insulin secretion response (Supplementary Fig. 3a-b and Supplementary Table 4). In patients with 153 newly diagnosed T2D, the p.Trp325Trp carriers showed a trend $(\mathrm{P}=0.12)$ to enhanced $\beta$-cell 154 sensitivity to glucose during the OGTT (Supplementary Fig. 3c). 
Taken together, all the human in vivo results show that T2D protection by the LoF variant

p.Arg138* is due to enhanced glucose-stimulated insulin secretion combined with enhanced

proinsulin conversion. The common T2D protective allele p.Trp325 shows a similar - albeit weaker

- metabolic phenotype suggesting it might also reduce ZnT8 function.

\section{SLC30A8 p.Arg138* variant in human iPSCs}

160

161

The majority of nonsense SLC30A8 alleles (including p.Arg138*) protecting against T2D are located in the first four exons of the eight-exon canonical islet SLC30A8 transcript ENST00000456015 and are predicted to undergo nonsense mediated decay (NMD), a cell surveillance pathway which reduces errors in gene expression by eliminating mRNA transcripts that contain premature stop codons. To confirm that the p.Arg $138 *$ allele indeed leads to haploinsufficiency through NMD, we used CRISPR-Cas9 to introduce the p.Arg138* variant into the SLC30A8 locus of the SB Ad3.1 human iPSC cell line (Supplementary Fig. 4a, Methods). Two hiPSC lines for the p.Arg138*-SLC30A8 variant (Clone B1 and A3) were generated and compared to an unedited p.Arg138Arg-SLC30A8 CRISPR hiPSC line. Both B1 and A3 clones were heterozygous with mono-allelic sequencing confirming the p.Arg138* variant in only one allele (Supplementary Fig. 4b). All hiPSC lines passed quality control checks including karyotyping and pluripotency (Supplementary Fig. 4c).

Accordingly, we subjected our SLC30A8-edited iPSCs to a previously published in vitro endocrine pancreas differentiation protocol ${ }^{14}$ (Supplementary Fig. 4d-k, Methods). At the end of the seven stage protocol, SLC 30A8 expression was significantly reduced in cells heterozygous for the

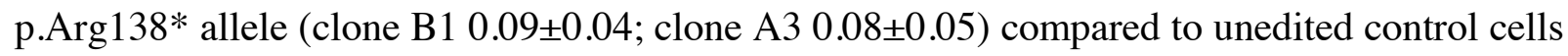
$(1.03 \pm 0.11)$ (Fig. 4a). Of note, p.Arg138* allele specific SLC30A8 expression was reduced

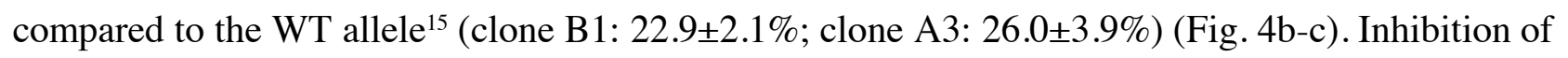
NMD by cyclohexamide increased expression of the p.Arg $138 *$ transcript more than the p.Arg138Arg transcript compared to DMSO control (clone B1:209 $\pm 52 \%$ and clone A3: $199 \pm 67 \%$ 
vs. clone B1: $161 \pm 30 \%$ and clone A3: $132 \pm 35 \%$, respectively, Fig. 4d-e). Taken together, these data

181 show that the protective p.Arg $138 *-S L C 30 A 8$ allele undergoes NMD, resulting in haploinsufficiency for SLC30A8.

\section{Impact of SLC30A8 loss in a human $\beta$-cell line}

184 Since human in vivo studies provided strong evidence for a role of the p.Arg138* on insulin

185 secretion and proinsulin processing, we studied the impact of SLC30A8 loss using siRNA mediated 186 knock down (KD) on both phenotypes in a well characterized human $\beta$-cell model EndoC- $\beta \mathrm{H} 1^{16}$ 187 (Methods). By siRNA, we achieved 55-65\% decrease in SLC30A8 mRNA ( $\mathrm{p}=0.008$ ) and protein $188 \quad(\mathrm{p}=0.016$, Fig. 5a-c).

189 KD of SLC30A8 had no significant effect on glucose- or tolbutamide-stimulated insulin secretion or 190 on insulin content (Fig. 5d-e) but basal insulin secretion was higher in siSLC30A8 transfected cells 191 compared to scrambled siRNA cells ( $\mathrm{p}=0.012$, Fig. 5d), and the inhibitory effect of diazoxide, a $192 \mathrm{~K}_{\text {ATP }}$ channel opener, on glucose-stimulated insulin secretion was reduced ( $\mathrm{p}=2 \times 10^{-3}$, Fig. $\left.5 \mathrm{~d}\right)$. We 193 measured the resting membrane conductance $\left(G_{m}\right)$, which principally reflects $K_{\text {ATP }}$ channel activity. 194 In control cells, $\mathrm{G}_{\mathrm{m}}$ was in agreement with that previously reported ${ }^{17}$. SLC30A8 $\mathrm{KD}$ reduced $\mathrm{G}_{\mathrm{m}}$ by $65 \%$ ( $\mathrm{p}=0.002$, Fig. 5f) without effect on cell size (Fig. 5g), an effect that correlated with reduced

196 expression of the two genes encoding the $\mathrm{K}_{\mathrm{ATP}}$ channel subunits SUR1 (ABCC8) and Kir6.2 197 (KCNJ11) (Fig. 5h). However, insulin secretion elicited by increasing extracellular $\mathrm{K}^{+}\left(\left[\mathrm{K}^{+}\right]_{\mathrm{o}}\right)$ to 50 $198 \mathrm{mM}$ (to depolarise the cells and open voltage-gated $\mathrm{Ca}^{2+}$ channels) and $16.7 \mathrm{mM}$ glucose was 199 significantly higher after $S L C 30 A 8 \mathrm{KD}$ (p=0.008, Fig. 5i). The proinsulin-insulin ratios (both total 200 and secreted hormones) were decreased in siSLC30A8 cells ( $\mathrm{p}<0.001$, Fig. 5j-k). Although mRNA 201 of the proinsulin processing genes $P C 1 / 3$ and $C P E$ was decreased, we could not detect a similar 202 reduction at the protein level (Fig. 51-n). 
RNA sequencing of $S L C 30 A 8 \mathrm{KD}$ cells ( $\mathrm{n}=3 \mathrm{vs.}$ ) replicated the reduction of $K C N J 11$ and $A B C C 8$

gene expression ( $\mathrm{p}=4.3 \times 10^{-3}$ and $\mathrm{p}=2.9 \times 10^{-5}$, respectively). In addition, expression of genes

involved in regulation of $\beta$-cell excitability was down-regulated, including KCNMA1 encoding a

$\mathrm{Ca}^{2+}$-activated $\mathrm{K}^{+}$channel $^{18}$ and TMTCl $\left(\mathrm{p}=6.8 \times 10^{-5}\right.$ and $2.9 \times 10^{-16}$, respectively) encoding an ER adapter protein influencing intracellular calcium levels. Also, expression of genes associated with

$208 \beta$-cell maturation and secretion was influenced by SLC30A8 KD with decreased expression of NKX6.1 and PDX1 and increased expression of SOX4, SOX6 and SOX11 (Fig. 5o-p).

In addition, we also observed increased AKT phosphorylation (pAKT-473) and improved cell survival under ER stress ( $<<0.017$, Fig. 5q-s), mechanisms which also could contribute to the overall protection by preserving $\beta$-cell mass ${ }^{19}$. Taken together, these data generated by disrupting SLC30A8 in a human $\beta$-cell pointed at multiple mechanisms including changes in proinsulin conversion, $\mathrm{K}_{\mathrm{ATP}}$ channel activity and cell viability.

\section{Metabolic phenotype of mice carrying the human SLC30A8 p.Arg138*}

Since neither global nor tissue specific Slc30a8 KD mouse models have recapitulated the human phenotype in carriers of the SLC30A8 p.Arg 138* variant, we tried to overcome this problem by using a mouse model carrying the Slc30a8 p.Arg 138* variant ${ }^{11}$. These mice do not express the truncated ZnT8 protein ${ }^{11}$. On a standard chow diet there was no evidence for enhanced insulin secretion ${ }^{11}$. However, we examined whether they might do so on a high fat diet (HFD). This was indeed the case (Fig. 6a-h), and the same differences in proinsulin/insulin and proinsulin/C-peptide ratios were seen as in humans. No changes were seen in insulin clearance.

\section{Impact of p.Arg138* on protein localization and cytosolic zinc distribution in INS-1 cells}

224 Although we found no evidence in either mouse or our human $\beta$-cell model to support the presence 225 of a truncated protein we explored the possibility of what might happen if a truncated protein 
proteins in a rat insulinoma cell line, INS-1e, showed distinct punctate distribution patterns, consistent with localization of the truncated ZnT8 protein to secretory granules, as previously observed with the full length protein ${ }^{20}$ (Supplementary Fig. 5a-c) Additionally, Western blot showed stable expression of truncated ZnT8 in native INS1e cells (Supplementary Fig. 5d).

To investigate the effects of a truncated $\mathrm{ZnT} 8$ protein on cytosolic free $\mathrm{Zn}^{2+}$, we used a geneticallyencoded $\mathrm{Zn}^{2+}$ sensor eCALWY-421 . Overexpression of the truncated protein ( $\mathrm{p}$.Arg138*) had no impact on cytosolic free $\mathrm{Zn}^{2+}$ when expressed in INS-1 WT cells ruling out a dominant negative effect for the truncated protein (Supplementary Fig. 5e-h).

\section{Influence of common SLC30A8 variants p.Trp325Arg in primary human islets}

While adult human islets show high levels of SLC 30A8 expression there was no reproducible effect of the p.Arg325Trp variant on SLC30A8 expression in human islets from cadaveric donors (Fig. carriers (Fig. 7b-e). The increased glucose responsiveness was observed at submaximal glucose stimulation $(6 \mathrm{mM})$ rather than at maximal glucose stimulation $(16.7 \mathrm{mM})$ (Fig. $7 \mathrm{~b}-\mathrm{c})$. Increasing glucose from $1 \mathrm{mM}$ to $6 \mathrm{mM}$ stimulated insulin secretion 2.2- and 2.7-fold in p.Arg325 and p.Trp325 carriers respectively, with no effect on insulin content (Fig. 7c-d). This secretion pattern echoes the one observed after siRNA of $S L C 30 A 8 \mathrm{KD}$ in EndoC- $\beta \mathrm{H} 1$. Insulin secretion in p.Trp325 carriers was also increased at high glucose $(16.7 \mathrm{mM})$ when co-exposed to depolarizing $\left[\mathrm{K}^{+}\right]_{\mathrm{o}}(70$ $\mathrm{mM}$ ) (Fig. 7e) as also seen after $S L C 30 A 8 \mathrm{KD}$ in EndoC- $\beta \mathrm{H} 1$.

As $S L C 30 A 8$ is highly expressed in human alpha cells ${ }^{1}$, we also measured glucagon secretion from the same islets (Fig. 7f). In islets from p.Arg325Arg donors, $6 \mathrm{mM}$ glucose inhibited glucagon secretion by $\sim 50 \%$ compared to $1 \mathrm{mM}$ glucose. In islets from p.Trp325Arg donors, glucagon secretion at $1 \mathrm{mM}$ glucose was reduced by $50 \%$ compared to p.Arg325Arg donors with no effect on glucagon content (Fig. 7f-g). 
251 We also explored whether the p.Trp325Arg variant would have trans-eQTL effects on genes

252 involved in insulin production and secretion ${ }^{22}$ (Fig. 7a). Expression of $P C S K 1(\mathrm{P}=0.041)$

253 and PCSK2 ( $\mathrm{P}=0.045)$ were reduced. Among the genes encoding for $\mathrm{K}_{\mathrm{ATP}}$ channels subunits

254 only $A B C C 8(\mathrm{P}=0.049)$ expression was significantly affected in islets from p.Trp325 carriers

255 compared to non-carriers (Fig. 7a). Taken together, the data suggest the common T2D-protective

256 allele (p.Trp325) may improve the response to a glucose challenge by enhancing insulin secretion

257 and possibly by reducing glucagon secretion in primary human islets.

\section{Discussion}

259 The current study demonstrates the strengths of using human models for studying the consequences 260 of LoF mutations in humans, particularly by demonstrating a stronger protective effect of 261 p.Arg138* in individuals carrying the common risk p.Arg325 allele on the same haplotype.

262 However, the minor p.Trp325 allele was also associated with protection against T2D albeit less 263 pronounced. This emphasizes the importance of taking into account the genetic background of the 264 human LoF carrier.

265 Whilst the data from all our sub-studies are consistent with increased glucose responsiveness, the 266 precise molecular mechanisms for these phenotypes, involvement of zinc and an explanation for 267 why there are discrepancies between humans and rodents remain elusive. In the IPS-derived beta268 like cells, the p.Arg 138* variant dramatically lowered expression with evidence of NMD resulting 269 in haploinsufficiency. Similarly, in the mouse model we were unable to detect the truncated 270 protein, but we could detect appreciable levels of RNA ${ }^{11}$.

271 The most reproducible finding in all sub-studies of p.Arg138* was enhanced glucose-stimulated 272 insulin secretion accompanied by increased conversion of proinsulin to C-peptide and insulin.

273 Carriers of p.Trp325 displayed a similar phenotype, which is in line with a previous study showing 274 impaired proinsulin conversion in carriers of the risk p.Arg325 allele ${ }^{23}$. There could also be other 
potential explanations for this effect, as it has been suggested that it takes some time for insulin to mature and become biologically active ${ }^{24,25}$. It is possible that the pronounced effects of the LoF mutation at 20 and 40 min of test meal could reflect such a mechanism.

The present and previous studies demonstrate that loss of ZnT8 function after silencing the murine gene reduces total cellular zinc content as well as free $\mathrm{Zn}^{2+}$ in the cytosol and granules ${ }^{7,10,20,26}$. LoF p.Arg138* (assuming no or minimal escape from NMD) is therefore likely to exert the same effects on intracellular zinc concentrations and may thus impact insulin secretion through intracellular mechanisms, including potential differences in $\mathrm{Zn}^{2+}$ secretion. Also, a recent study showed that the p.Arg325Arg variant was associated with higher islet zinc concentrations ${ }^{27}$. In the present study over-expression of the LoF mutation p.Arg138* in INS-1 cells did not result in changes in cytosolic zinc concentrations leaving a reduction of zinc in insulin granules as a plausible explanation which still needs to be experimentally confirmed.

In support of a protective effect of lowering intracellular zinc concentrations on development of diabetes, in the CNS, $\mathrm{Zn}^{2+}$ plays an important role as a regulator of cellular excitability ${ }^{28}$ and $\mathrm{Zn}^{2+}$ has been reported to activate $\mathrm{K}_{\text {ATP }}$ channels ${ }^{29}$, inhibit L-type voltage-gated $\mathrm{Ca}^{2+}$ channels and inhibit insulin secretion ${ }^{30}$.

291 Taken together, our data consistently demonstrate that heterozygosity for a LoF mutation p.Arg $138 *$ and homozygosity for a common variant p.Trp325Trp of the SLC30A8 are associated with increased insulin secretion capacity and lower risk of T2D without any negative effect. Therefore, ZnT8 remains an appealing safe target for antidiabetic therapy preserving $\beta$-cell function. 


\section{Methods}

\section{Human study population}

The Botnia Study has been recruiting patients with T2D and their family members in the area of

five primary health care centers in western Finland since 1990. Individuals without diabetes at baseline (relatives or spouses of patients with T2D) have been invited for follow-up examinations every 3-5 years ${ }^{12}$. The Prevalence, Prediction and Prevention of diabetes (PPP)-Botnia Study is a population-based study in the same region including a random sample of 5,208 individuals aged 18 to 75 years from the population registry ${ }^{31}$. Diabetes Registry Vaasa (DIREVA) is regional diabetes registry of $>5000$ diabetic patients from Western Finland (Botnia region) ${ }^{\mathbf{3 2}}$. In the current study, we included $>14,000$ individuals (Botnia family study=5678, PPP=4862, and DIREVA=3835). All participants gave their written informed consent and the study protocol was approved by the Ethics Committee of Helsinki University Hospital, Finland (the Botnia studies) and the Ethics Committee of Turku University Hospital (DIREVA).

Oral Glucose Tolerance Test (OGTT) and test meal: Subjects maintained a weight-maintaining diet and avoided vigorous exercise for 3 days prior to the OGTT or test meal, which were performed after an overnight fast. Height, weight, hip and waist circumferences, fat percentage (\%,

315 bioimpedance analyzer) and blood pressure (sitting, 3 measurements after 5 min rest) were measured. The participants ingested $75 \mathrm{~g}$ dextrose (in a couple of minutes, OGTT) or a $526 \mathrm{kcal}$ mixed meal (in 10 minutes, test-meal: $76 \mathrm{~g}$ carbohydrate, $17 \mathrm{~g}$ protein and $15 \mathrm{~g}$ fat). Blood samples were drawn from an antecubital vein for plasma (P-) glucose and serum (S-) insulin and C-peptide at 0, 30, 120 min during the OGTT; for P-glucose, P-glucagon, S- insulin, S-C-peptide, S-zinc, and total S-GLP-1 at 0, 20, 40, 70, 100, 130, 160 and 190 min during the test meal. Test meal samples for S-FFA were collected at 0,40 and $120 \mathrm{~min}$ and for S-proinsulin at 0, 20,40 and $130 \mathrm{~min}$, respectively. Urine was collected between $0-70$ and $70-190$ min for the determination of glucose and zinc excretion during the test meal. 
Intravenous Glucose Tolerance Test (IVGTT): IVGTT group consists of total 849 (male- 403,

female-446) individuals with an average age of 51 years. An antecubital polyethylene catheter was placed to one hand for the infusion of $0.3 \mathrm{~g} / \mathrm{kg}$ body weight of glucose (maximum dose $35 \mathrm{~g}$ ) intravenously for $2 \mathrm{~min}$. A retrogradely positioned wrist vein catheter was placed in the other hand, held in a heated $\left(70^{\circ} \mathrm{C}\right)$ box in order to arterialize the venous blood. Arterialized blood samples were drawn at $0,2,4,6,8,10,20,30,40,50$ and 60 min for P-glucose and S-insulin.

Biochemical measurements: P-glucose was analyzed using glucose oxidase (Beckman Glucose

331 Analyzer, Beckman Instruments, Fullerton, CA, USA; Botnia Family Study) or glucose dehydrogenase method (Hemocue, Angelholm, Sweden; PPP-Botnia and test meal studies). In the Botnia Family study, S-insulin was measured by radioimmunoassay (RIA, Linco; Pharmacia,

334 Uppsala, Sweden), enzyme immunoassay (EIA; DAKO, Cambridgeshire, U.K.) or 335 fluoroimmunometric assay (FIA, AutoDelfia; Perkin Elmer Finland, Turku, Finland). For the analysis, insulin concentrations obtained with different assays were transformed to cohere with those obtained using the EIA. The correlation coefficient between RIA and EIA as well as between 338 FIA and EIA was $0.98(\mathrm{P}<0.0001)$. S-insulin was measured by the FIA in baseline visit of PPP339 Botnia and the test meal study (correlation co-efficient 0.98). S-proinsulin was measured using RIA 340 (Linco; Pharmacia, Uppsala, Sweden, OGTT data) or EIA (Mercodia AB, Uppsala, Sweden; test341 meal data), and P-glucagon using RIA (EMD Millipore, St. Charles, MO; OGTT data) or EIA 342 (Mercodia AB, Uppsala, Sweden; test-meal data). S-FFA was measured by an enzymatic 343 colorimetric method (Wako Chemicals, Neuss, Germany). Serum total cholesterol, HDL and 344 triglyceride concentrations were measured with Cobas Mira analyzer (Hoffman LaRoche, Basel, 345 Switzerland), and since 2006 with an enzymatic method (Konelab 60i analyser; Thermo Electron 346 Oy, Vantaa, Finland). Serum LDL cholesterol was calculated using the Friedewald formula. Blood 347 collected in tubes containing DPP4-inhibitors was used for radioimmunoassay ${ }^{33}$ for total P-GLP-1 348 (intact GLP-1 and the metabolite GLP-1 9-36 amide) during test meal. 
Serum and urine samples for zinc were collected in trace element tubes (Beckton Dickinson, NJ,

USA) and S- and U-zinc analyzed by two commercial laboratories: NordLab (Oulu, Finland; atom for P-albumin ( $\mathrm{r}=0.34$, p 0.008 Nordlab, $\mathrm{r}=0.34$, p 0.03 Synlab).

Corrected insulin response (CIR) was calculated for test meal (at $20 \mathrm{~min}$ ) and OGTT (at $30 \mathrm{~min}$.) using the formula $\operatorname{CIR}(\mathrm{t})=\operatorname{Ins}(\mathrm{t}) /[\mathrm{Gluc}(\mathrm{t}) \bullet(\operatorname{Gluc}(\mathrm{t})-3.89)]$, where $\operatorname{Ins}(\mathrm{t})$ and Gluc(t) are insulin (in $\mathrm{mU} / \mathrm{L}$ ) and glucose concentrations (in $\mathrm{mmol} / \mathrm{L}$ ) at sample time point $\mathrm{t}(\mathrm{min})^{34}$. Estimation of Insulin clearance index was done on the model based estimation of glucose-, insulin- and C-peptide curves during the test meal using the equation AUC(ISR) / [(AUC(ins)+(I(basal)-I(final) • MRT(ins)], where AUC(ISR) is the area under the curve of insulin secretion rate, AUC(ins) is the area under the curve of insulin concentration, I(final) is insulin concentration at the end, and I(basal) insulin concentration at the beginning of the study ${ }^{35}$. MRT(ins) is the mean residence time of insulin, and was assumed to be 27 minutes as reported previously ${ }^{36}$.

Genotyping: We analyzed genotype data for rs13266634 (p.Trp325Arg) and rs200185429

364 (p.Arg138*) for three cohorts genotyped with different genome-/exome-wide chips: the Botnia 365 family cohort (Illumina Global Screening array-24v1, genotyped at Regeneron Pharmaceuticals), PPP-Botnia (Illumina HumanExome v1.1 array, genotyped at Broad Institute ${ }^{3}$ ) and DIREVA

367 (Illumina Human CoreExome array-24v1, genotyped at LUDC). For the Botnia family cohort, 368 genotype data for p.Arg $138^{*}$ were imputed (info score $>0.95$ ) from the available GWAS data by 369 phasing using SHAPT-IT v $2^{37}$ and imputing using the GoT2D reference panel ${ }^{38}$ by IMPUTEv $2^{39}$. 370 The carrier status of imputed p.Arg $138 *$ was additionally confirmed from exome sequencing data.

371 Genotyping (p.Trp325Arg and p.Arg138*) the family members participating in the genotype based 372 recall study (test meal study) was performed using TaqMan (Applied Biosystems, Carlsbad, CA). 373 The genotype distribution of both variants was in accordance with Hardy-Weinberg equilibrium in 
all the cohorts. We did not detect any Mendelian errors in the families.

375 Genetic Association Analysis: All the quantitative traits were inversely normally transformed before the analyses. The family-based recall study included only non-diabetic subjects during test meal and analysis of data was performed using family-based association analyses adjusting for age, sex, BMI, and other covariates if appropriate, using QTDT (v2.6.1 $)^{40}$. The significance levels were derived from 100,000 permutations as implemented in QTDT. Also, the OGTT study included only non-diabetic subjects. The association analysis was performed using mixed linear model considering genetic relatedness among samples as implemented in GCTA (v1.91) ${ }^{41}$.

Study participants and their clinical measurements in Verona Newly Diagnosed Diabetes Study ongoing study aiming at building a biobank of patients with newly diagnosed (within the last six months) type 2 diabetes. Patients are drug-naïve or, if already treated with antidiabetic drugs, undergo a treatment washout of at least one week before metabolic tests are performed ${ }^{42}$. Each subject gave informed written consent before participating in the research, which was approved by the Human Investigation Committee of the Verona City Hospital. Metabolic tests were carried out on two separate days in random order ${ }^{42}$. Plasma glucose concentration was measured in duplicate with a Beckman Glucose Analyzer II (Beckman Instruments, Fullerton, CA, USA) or an YSI 2300 Stat Plus Glucose\&Lactate Analyzer (YSI Inc., Yellow Springs, OH, USA) at bedside. Serum Cpeptide and insulin concentrations were measured by chemiluminescence as previously described ${ }^{42}$. The analysis of the glucose and C-peptide curves during the OGTT was carried out with a 394 mathematical model as described previously ${ }^{42}$. This model was implemented in the SAAM 1.2 software (SAAM Institute, Seattle, WA) to estimate its unknown parameters. Numerical values of the unknown parameters were estimated by using nonlinear least squares. Weights were chosen optimally, i.e., equal to the inverse of the variance of the measurement errors, which were assumed to be additive, uncorrelated, with zero mean, and a coefficient of variation (CV) of 6-8\%, A good fit 
of the model to data was obtained in all cases and unknown parameters were estimated with good

precision. In this paper we report the response of the beta cell to glucose concentration

401 (proportional control of beta cell function), which in these patients accounts for $93.2 \pm 0.3 \%$ of the

insulin secreted by the beta cell in response to the oral glucose load. Genotypes were assessed by

the high-throughput genotyping Veracode technique (Illumina Inc, CA), applying the GoldenGate

404 Genotyping Assay according to manufacturer's instructions. Hardy-Weinberg equilibrium was tested by chi-square test. Variant association analyses were carried out by generalized linear models

(GLM) as implemented in SPSS 25.0 and they were adjusted for a number of potential confounders,

407 including age, sex and BMI.

\section{iPSC generation, differentiation and genome editing}

iPSC generation and maintenance: The human induced pluripotent stem cell line (hiPSC) SB

Ad3.1 was previously generated and obtained through the IMI/EU sponsored StemBANCC

Human CytoSNP-12v2.1 beadchip (Illumina \#WG-320-2101), DAPI-stained metaphase counting

419 and mFISH, flow cytometry for pluripotency markers (BD Biosciences \#560589 and 560126), and mycoplasma testing (Lonza \#LT07-118).

\section{CRISPR-Cas9 mediated generation of p.Arg138* human induced pluripotent stem cell line:}


additional BlastN search (www.ensembl.org) to confirm specificity and identified no additional offtarget sites. The gRNA (AGCAGGTACGGTTCATAGAG) was sub-cloned into the $B s b I$ restriction sites in pX330 ${ }^{44}$ plasmid that was previously modified to contain a puromycin selection cassette.

Single strand oligonucleotides for homology-directed repair (HDR) were synthesised by

Eurogentec, stabilised by addition of a phosphorothioate linkage at the 5' end, and contained two nucleotide changes: i) the T2D-protective nonsense mutation at codon-138 (c.412C>T, p.Arg138*), which also mutated the PAM sequence, and ii) a silent missense mutation at codon-139 (c.417A $>$ T, p.Ala139Ala) to introduce an $A l u \mathrm{I}$ restriction site for genotyping.

Human iPSCs were co-transfected with SLC30A8-px330-puromycin resistant vectors and HDR oligos using Fugene6 according to manufacturer's guidelines (Promega \#E2691). Following transient puromycin-selection, single clones were picked and expanded as described previously ${ }^{45}$. sequencing was performed by TA-cloning (pGEM®-T Easy Vector System; Promega \#A1360) of the PCR amplicons. The control hiPSC line (p.Arg138Arg) was generated from hiPSC cells that went through the CRISPR pipeline without being edited at the SLC30A8 locus. The two p.Arg138* clones (A3 and B1) and the unedited control line (p.Arg138Arg) passed quality control checks that included repeat chromosome counting and pluripotency testing.

In vitro differentiation of hiPSCs towards Beta-like cells: Directed differentiation of hiPSCs

444 towards beta-like cells was performed using a previously published protocol ${ }^{14,46}$. hiPSCs were 445 seeded on Growth Factor Reduced Matrigel-coated CellBind 12-well tissue culture plates (Corning 446 \#356230 \& \#3336) at a cell density of $1.3 \times 10^{6}$ in mTesR1 (Stem Cell Technologies \#05850) with $44710 \mu \mathrm{M}$ Y-27632 dihydrochloride (Abcam \#ab120129). The following morning, hiPSCs were fed 448 mTesR1 media $>4$ hours before starting the seven-stage differentiation protocol. 
Stage 1 (Definitive Endoderm): Cells were washed once with PBS before adding $0.5 \%$ bovine serum albumin (BSA; Roche \#10775835001) MCDB131 media [(ThermoFisher Scientific \#10372019) containing 1x Penicillin-Streptomycin (Sigma \#P0781), 1.5 g/L sodium bicarbonate (ThermoFisher Scientific \#25080060), 1x GlutaMAX ${ }^{\mathrm{TM}}$ (ThermoFisher Scientific \#35050038) and $10 \mathrm{mM}$ Glucose (ThermoFisher Scientific \#A2494001)] supplemented with $100 \mathrm{ng} / \mathrm{mL}$ Activin A 454 (Peprotech \#120-14) and $3 \mu$ M CHIR 99021 (Axon Medchem \#1386). On day 2 and 3, cells were cultured with $0.5 \%$ BSA MCDB131 media supplemented with either $100 \mathrm{ng} / \mathrm{mL}$ Activin A and 0.3 $\mu$ M CHIR 99021 (day 2) or with 100 ng/mL Activin A alone (day 3).

Stage 2 (Primitive Gut Tube): Cells were cultured for 48 hours in 0.5\% BSA MCDB131 media with $0.25 \mathrm{mM}$ ascorbic acid (Sigma \#A4544) and $50 \mathrm{ng} / \mathrm{mL}$ KGF (PeproTech \#100-19).

Stage 3 (Posterior Foregut): Cells were cultured for two days in 2\% BSA MCDB131 media supplemented with $1 \mathrm{~g} / \mathrm{L}$ sodium bicarbonate, $0.25 \mathrm{mM}$ ascorbic acid, $0.5 \mathrm{x}$ Insulin-Transferrin-

461 Selenium-Ethanolamine (ITS-X; ThermoFisher Scientific \#51500056), $1 \mu \mathrm{M}$ retinoic acid (RA; 462 Sigma-Aldrich \#R2625), $0.25 \mu \mathrm{M}$ Sant-1 (Sigma-Aldrich \#S4572), 50 ng/ml KGF, $100 \mathrm{nM}$ LDN193189 (Stemgent \#04-0074), and 100 nM $\alpha$-Amyloid Precursor Protein Modulator (Merck $464 \quad \# 565740)$.

465 Stage 4 (Pancreatic Endoderm): Cells were cultured for three days in 2\% BSA MCDB131 media 466 supplemented with $1 \mathrm{~g} / \mathrm{L}$ sodium bicarbonate, $0.25 \mathrm{mM}$ ascorbic acid, $0.5 \mathrm{x}$ ITS-X, $0.1 \mu \mathrm{M}$ RA, 0.25 $467 \mu$ M Sant-1, 2 ng/ml KGF, 200 nM LDN193189 and 100 nM $\alpha$-Amyloid Precursor Protein 468 Modulator.

469 Stage 5 (Endocrine Progenitors): Cells remained in planar culture for three days in 2\% BSA 470 MCDB131 media supplemented with $20 \mathrm{mM}$ final glucose, $0.5 \mathrm{x}$ ITS-X, $0.05 \mu \mathrm{M}$ RA, $0.25 \mu \mathrm{M}$ 471 Sant-1, 100 nM LDN193189, $10 \mu \mathrm{M}$ ALK5 Inhibitor II (Enzo Life Sciences \#ALX-270-445), $1 \mu \mathrm{M}$ 
3,3,5-Triiodo-L-thyronine sodium salt (T3; Sigma-Aldrich \#T6397), $10 \mu \mathrm{M}$ zinc sulfate

heptahydrate (Sigma \# Z0251), and $10 \mu \mathrm{g} / \mathrm{mL}$ heparin sodium salt (Sigma \#H3149).

Stage 6 (Endocrine Cells): Cells remained in planar culture for six days in 2\% BSA MCDB131

media supplemented with $20 \mathrm{mM}$ final glucose, 0.5x ITS-X, $100 \mathrm{nM}$ LDN193189, $10 \mu \mathrm{M}$ ALK5

Inhibitor II, $1 \mu \mathrm{M}$ T3, $10 \mu \mathrm{M}$ zinc sulfate heptahydrate, and $100 \mathrm{nM} \gamma$-Secretase Inhibitor XX

(Merck Millipore \#565789).

Stage 7 (Beta-like Cells): Cells remained in planar culture for another six days in $2 \%$ BSA

MCDB131 media supplemented with $20 \mathrm{mM}$ final glucose, 0.5x ITS-X, $10 \mu \mathrm{M}$ ALK5 Inhibitor II,

R248 (SelleckChem \#S2841), and $10 \mu \mathrm{M}$ zinc sulfate heptahydrate.

\section{Quantification of SLC30A8 gene expression in Beta-like Cells derived from CRISPR-edited}

483 hiPSCs: Expression of SLC30A8 was measured at the end of stage 7 using quantitative PCR

484 (qPCR). Briefly, RNA was extracted using TRIzol Reagent (Life Technologies \#15596026)

Transcription Kit (Promega \#A5000). qPCR was performed using 40 ng of cDNA, TaqMan® Gene

487 Expression Master Mix (Applied Biosystems \#4369017) and primer/probes for SLC30A8

488 (Hs00545182_m1) or the housekeeping gene TBP (Hs00427620_m1). Gene expression was

489 determined using the $\triangle \triangle \mathrm{CT}$ method by first normalizing to $T B P$ and then to the control

490 p.Arg138Arg sample (n=6-7 wells from two differentiations).

491 Allele-specific SLC30A8 expression in Beta-like Cells derived from CRISPR-edited hiPSCs:

492 Stage 7 cells were treated with $100 \mu \mathrm{g} / \mathrm{mL}$ cycloheximide (Sigma \#C4859) or DMSO (Sigma 493 \#D2650) for four hours at $37^{\circ} \mathrm{C}^{47}$ before harvesting for RNA and cDNA synthesis as above. Allele 494 specific expression was measured using the QX10 Droplet Digital PCR System and C1000 Touch 495 Thermal Cycler according to manufacturer's guidelines (Bio-Rad). Custom primers and probes for 
the detection of p.Arg138* variant were designed using Primer3Plus (Applied Biosystems):

software (Bio-Rad) and presented as a ratio of wildtype to HDR-edited allele expression ( $\mathrm{n}>3$ wells

501 from two differentiations).

\section{EndoC- $\beta$ H1 culture}

The results obtained in EndoC- $\beta \mathrm{H} 1$ are from two distinct teams (Helsinki and Oxford) with medium and grown on a matrix as described previously ${ }^{48}$ and tested negative for mycoplasma.

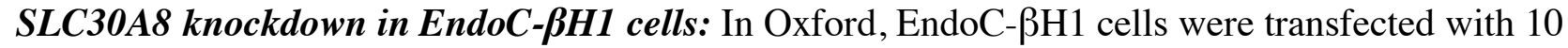
nM siRNA (either SMARTpool ON-TARGETplus SLC30A8 or scramble [Dharmacon \#L-00752901]) and Lipofectamine RNAiMAX (Life Technologies \#13778-075) according to manufacturer's instructions for a total of 72 hours. In Helsinki, EndoC- $\beta$ H1cells were transfected using for human SLC30A8 gene (Dharmacon; L-007529-01) and ON-TARGETplus Non-targeting pool (siNT or Scramble) (Dharmacon; D-001810-10-05) were used following the protocol as described previously ${ }^{49}$. Cells were harvested $96 \mathrm{~h}$ post-transfection for further studies.

515 Insulin secretion measurements in EndoC-BH1 cells: In Oxford, cells were subjected to static 516 insulin secretion assays $72 \mathrm{hrs}$ after siRNA transfection as described previously ${ }^{50}$, apart from the 517 following modifications: cells were stimulated for $1 \mathrm{hr}$ with $1 \mathrm{mM}$ glucose, $20 \mathrm{mM}$ glucose, $1 \mathrm{mM}$ 518 glucose $+200 \mu \mathrm{M}$ tolbutamide, or $20 \mathrm{mM}$ glucose $+500 \mu \mathrm{M}$ diazoxide. Insulin levels were measured in both supernatants and cells using the Insulin (human) AlphaLISA Detection Kit and 
bioRxiv preprint doi: https://doi.org/10.1101/436030; this version posted October 22, 2018. The copyright holder for this preprint (which was not certified by peer review) is the author/funder, who has granted bioRxiv a license to display the preprint in perpetuity. It is made available under aCC-BY-NC-ND 4.0 International license.

EnSpire Alpha Plate Reader (Perkin Elmer \#AL204C and \#2390-0000, respectively). Cell count per well was measured via CyQUANT Direct Cell Proliferation Assay (Thermo Fisher\# C35011). Data are presented as insulin secretion normalized to percentage of insulin content from Control condition. RNA extraction, cDNA synthesis, and qRT-PCR was performed as above (SLC30A8 gene expression in CRISPR-edited hiPSCs derived beta like cell section) to determine SLC30A8 knockdown and expression of the $\mathrm{K}_{\mathrm{ATP}}$ channel genes (ABCC8 Hs01093752_m1 and KCNJ11 Hs00265026_s1; ThermoFisher Scientific). In Helsinki, EndoC- $\beta$ H1 cells were transfected with 20nM siRNA and Scramble control. Following 96h of siRNA transfection, cells were incubated overnight in $1 \mathrm{mM}$ glucose containing EndoC- $\beta \mathrm{H} 1$ culture medium. One hour prior to glucose stimulation assay, the media was replaced by $\beta$ KREBS (Univercell Biosolution S.A.S., France) without glucose. Cells were stimulated with $16.7 \mathrm{mM}$ glucose and $50 \mathrm{mM} \mathrm{KCl}$ (Sigma-Aldrich) in $\beta$ KREBS for $30 \mathrm{~min}$ at $37^{\circ} \mathrm{C}$ in a $\mathrm{CO}_{2}$ incubator. The cells were then washed and lysed with TETG (Tris pH8, Trito X-100, Glycerol, $\mathrm{NaCl}$ and EGTA) solution (Univercell Biosolution S.A.S., France) for the measurement of total insulin content. Secreted and intracellular insulin were measured using a commercial human insulin Elisa kit (Mercodia AB, Uppsala, Sweden) as per manufacturer's instructions (Helsinki).

Electrophysiological measurements in EndoC-BH1 cells (Oxford): SLC $30 A 8$ was knocked down in EndoC- $\beta \mathrm{H} 1$ as above. $\mathrm{K}^{+}{ }_{\mathrm{ATP}}$ channel conductance was measured in a perforated patch whole cell configuration, and patch-clamped using an EPC 10 amplifier and HEKA pulse software. KREBS extracellular solution was perfused in at $32^{\circ} \mathrm{C}$ and contained: $138 \mathrm{mM} \mathrm{NaCl}, 3.6 \mathrm{mM} \mathrm{KCl}, 0.5 \mathrm{mM}$ $\mathrm{MgSO}_{4}, 10 \mathrm{mM}$ HEPES, $0.5 \mathrm{mM} \mathrm{NaH} \mathrm{PO}_{4}, 5 \mathrm{mM} \mathrm{NaHCO}{ }_{3}, 1.5 \mathrm{mM} \mathrm{CaCl}_{2}, 1 \mathrm{mM}$ glucose and 100 $\mu \mathrm{M}$ Diazoxide (Sigma-Aldrich \#D9035). The perforation of the membrane was achieved using an intra-pipette solution containing: $0.24 \mathrm{mg} / \mathrm{mL}$ amphotericin B, $128 \mathrm{mM}$ K-gluconate (Sigma \#Y0000005 and G4500 respectively), $10 \mathrm{mM} \mathrm{KCl,} 10 \mathrm{mM} \mathrm{NaCl}, 1 \mathrm{mM} \mathrm{MgCl} 2,10 \mathrm{mM}$ HEPES,

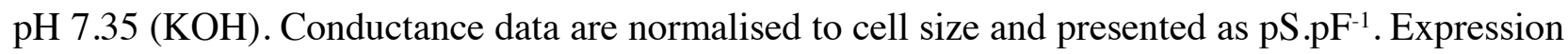


of $A B C C 8, K C N J 11, B 2 M$, and $T B P$ were measured via qPCR as above (SLC30A8 gene expression in CRISPR-edited hiPSCs derived beta like cell section).

Insulin and Proinsulin secretion and content (Helsinki): For the measurement of secreted insulin or proinsulin in the supernatant, 96h post-transfected cells were washed twice with $1 \mathrm{X}$ PBS and incubated with fresh EndoC- $\beta \mathrm{H} 1$ culture medium for next $24 \mathrm{~h}$. Secreted and intracellular insulin and proinsulin were measured using a commercial human insulin Elisa and human proinsulin Elisa kit from Mercodia (Mercodia AB, Uppsala, Sweden). Total cellular protein content was also determined with the BCA protein assay kit (Thermo Scientific, Pierce). Proinsulin to insulin ratio was calculated by dividing the respective values measured from the supernatant and the cells

$554(\mathrm{pmol} / \mathrm{L})$.

Immunoblotting (Helsinki): Total cellular protein was prepared with Laemmli buffer and resolved using Any kD Mini-Protean-TGX gel (Bio-Rad). Immunoblot analysis was performed by overnight incubation of with primary antibodies against ZNT8 (Abcam; \#ab136990; 1:500), PC1/3 (Cell Signaling; \#11914; 1:1000), CPE (BD Bioscience; \#610758; 1:1000), Phospho-AKT-Ser473 (Cell Signaling; \#4060; 1:1000), AKT (Santa-Cruz; \#SC-8312; 1:500). The membranes were further incubated with species-specific HRP-linked secondary antibodies (1:5000) and visualization was performed following ECL exposure with ChemiDoc XRS+ system and Image Lab Software (BioRad). A loading control of either alpha-Tubulin (Sigma; T5168; 1:5000) or beta-actin (Sigma; A5441; 1:5000) was performed on the same blot for all western blot data. Densitometric analysis of bands from image were calculated using Image $\mathbf{J}$ (Media Cybernetics) software and intensities compared as ZNT8, PC1/3, phosphor-AKT-Ser473 to tubulin; CPE to beta-actin. 
standard MTT [3-(4,5-dimethylthiazol-2-yl)-2,5-diphenyltetrazolium bromide] assay. All the treatments were performed on cells with equal seeding density $\left(5 \times 10^{4}\right.$ cells/well $)$ in 96 wells plate. The purple formazan crystals generated after $2 \mathrm{~h}$ incubation with MTT buffer were dissolved in DMSO, and the absorbance was recorded on a microplate reader at a wavelength of $540 \mathrm{~nm}$.

RNA (mRNAs) sequencing of EndoC-BH1 cells: For RNA sequencing post 96h siScramble $(n=3)$ or siSLC30A8 $(n=3)$ transfected EndoC- $\beta$ H1 cells were used and the total RNA was extracted with Macherey-Nagel RNA isolation kit as per manufacturer's instruction. RNA sequencing was performed using Illumina TruSeq-mRNA library on NextSeq 500 system (Illumina) with an average of $>15$ million paired-end reads $(2 \times 75$ base pairs $)$. RNA sequencing reads were aligned to hg38 using STAR (Spliced Transcripts Alignment to Reference) ${ }^{51}$, genome annotations were obtained from the GENCODE (Encyclopedia of Genes and Gene Variants) v22 $2^{52}$ program, and reads counting were done using featureCounts ${ }^{53}$. Further downstream analysis was perform using edgR ${ }^{54}$ software package, low expressed ( $<1$ average count per million) genes were removed, read counts were normalized using TMM ${ }^{55}$ (trimmed mean of M-values), differential expression analysis was performed using method similar to Fisher's Exact Test and corrected for multiple testing using FDR (1\%).

Data Analyses: Data are reported as mean (SEM). Statistical analyses were performed using Prism

Student's t-test as indicated.

\section{Mouse Model}

Animals: All procedures were conducted in compliance with protocols approved by the Regeneron 590 Pharmaceuticals Institutional Animal Care and Use Committee. The Slc30a ${ }^{\text {Tgp.Arg1 } 138^{*} \text { mouse line is }}$ made in pure C57B1/6 background by changing nucleotide 409 from $\mathrm{T}$ into $\mathrm{C}$ in exon 3, which 
cassette flanked by loxP sites inserted at intron 3, deleting 29 bp of endogenous intron 3 sequence.

Mice were housed (up to five mice per cage) in a controlled environment (12-h light/dark cycle, 22C, 60-70\% humidity) and fed ad libitum with either chow (Purina Laboratory 23 Rodent Diet 5001, LabDiet) or high-fat diet (Research Diets, D12492; 60\% fat by calories) starting at age of 20 weeks. All data shown are compared to their respective WT littermates.

Glucose Tolerance Test: Mice were fasted overnight (16 hr) followed by oral gavage of glucose (Sigma) at $2 \mathrm{~g} / \mathrm{kg}$ body weight. Blood samples were obtained from the tail vein at the indicated times and glucose levels were measured using the AlphaTrak2 glucometer (Abbott). Submandibular bleeds for insulin were done at 0,15 , and 30 min post-injection.

Hormone measurements: Submandibular bleeds of either overnight fasted or fed animals were done in the morning. Plasma insulin or proinsulin was analyzed with the mouse insulin/proinsulin EIA (Mercodia AB, Uppsala, Sweden), and C-peptide with the mouse C-peptide EIA (ALPCO). All EIAs were performed according to the manufacturer's instructions.

Data Analyses for mouse studies: Data are reported as mean (SEM). Statistical analyses were performed using Prism 6.0 (GraphPad Software). All parameters were analyzed by two-way ANOVA or Unpaired Student's t-test as indicated.

\section{Expression of p.Arg138* mutation in INS1E}

INS-1E cells ${ }^{56}$ were used for transient transfection of pcDNA3.1(+)-p.Arg138* construct fused to fluorescent m-Cherry at C-terminus using transfection reagent Viromer according to the manufacturer's instructions. After transfections cells were collected at 24, 48, 72 and 96 hours and analysed by western blot analysis using mCherry (600-401-P16, Rockland) antibody. Untransfected cells were used as control and tubulin as a loading control. Two days after transient transfections with either p.Arg138*-mCherry (INS1E), p.Arg138*-HA or p.Arg138*-Myc-His construct (INS1E), cells were washed with PBS twice and fixed using 4\% paraformaldehyde for 15 min at 
617 room temperature. Cells were permeabilized with $0.2 \%$ Triton X-100 in phosphate-buffered saline 618 (PBS) for 10 mins and to prevent unspecific binding were further blocked for $1 \mathrm{~h}$ with 5\% FBS in 619 PBS. INS1E cells transfected with either p.Arg138*-HA or p.Arg138*-Myc-His construct were 620 incubated with the primary antibody (HA antibody: MMS-101P, Biolegend; His antibody: D291621 A48, MBL; insulin antibody: A0564, DAKO), overnight at $4^{\circ} \mathrm{C}$. Secondary antibodies were conjugated to Alexa Fluor 488 (Molecular Probes). Cells transfected with mCherry construct were imaged after 48 and 96 hours (INS1E) in order to visualize subcellular localization at different time 624 points.

Measurements of cytosolic zinc in INS-1(832/13) cells

Cell culture: INS-1 (823/13) cells were grown in RPMI 1640 medium (Sigma-Aldrich, UK) supplemented with $10 \%$ (v/v) foetal bovine serum (FBS), 2 Mm L-glutamine, 0.05 mM 2mercaptoethanol, $10 \mathrm{mM}$ HEPES (Sigma-Aldrich), $1 \mathrm{mM}$ sodium pyruvate (GIBCO, France), 2 mM L-glutamine and antibiotics (100 $\mu \mathrm{g} / \mathrm{ml}$ Streptomycin and $100 \mathrm{U} / \mathrm{ml}$ penicillin). Cells were maintained in $95 \%$ oxygen, $5 \%$ carbon dioxide at $37^{\circ} \mathrm{C}$.

631 Co-transfection: Cells were seeded on sterile coverslips at $60 \%$ confluence and co-transfected 632 using lipofectamine 2000 (Invitrogen, USA) according to the manufacturer's instructions, with 633 either the empty construct (EV) or the rare-truncated variant (c-Myc tag, R138X) construct and the 634 Förster Resonance Energy transfer sensors (FRET), eCALWY-4 vector (free cytosolic zinc 635 measurements).

636 Protein extraction and Western (immuno-) blotting analysis: For protein extraction, RIPA buffer 637 (1\% Triton $\mathrm{X}-100,1 \%$ sodium deoxycholate, $0.1 \%$ SDS, $0.15 \mathrm{mM} \mathrm{NaCl}, 0.01 \mathrm{M}$ sodium Phosphate $638 \mathrm{pH7.2)}$ was used for lysis. Protein extracts were resolved in SDS-page (12\% vol/vol acrylamide) 639 and transferred to a polyvinylidene fluoride (PVDF) membrane, followed by blocking for 1 hour, 640 immunoblotting with either c-Myc anti-mouse SLC30A8 (1:400) and the secondary anti-mouse 
641 antibody (1:10000, Abcam), and then the mouse monoclonal anti-tubulin (1:10000) and secondary

642 anti-mouse for tubulin (1:5000). Chemiluminescence detection reagent (GE Healthcare) was used 643 before exposing to hyperfilms.

644 Immunocytochemistry: Cells were fixed in 4\% (v/v) Phosphate-buffered saline/Paraformaldehyde 645 (PFA). Cells were permeabilized in $0.5 \%(\mathrm{w} / \mathrm{v}) \mathrm{PBS} /$ TritonX-100 and further saturated with 646 PBS/BSA $0.1 \%$. Cells were then incubated for 1 hour with the primary antibody, anti-c-Myc mouse 647 antibody (1:200) followed by the secondary Alexa Fluor ${ }^{\circledR} 568 \mathrm{~nm}$ anti-mouse IgG $(\mathrm{H}+\mathrm{L}, 1: 1000$ 648 Life Technologies, USA). Coverslips were mounted with mounting medium containing DAPI 649 (Vectashield, USA) on microscope slides (ThermoScientific). Imaging was performed on a Nikon 650 Eclipse Ti microscope equipped with a 63x/1.4NA objective, spinning disk (CAIRN, UK) using a 651405,488 and $561 \mathrm{~nm}$ laser lines, and images were acquired with an ORCA-Flash 4.0 camera 652 (Hamamatsu) Metamorph software (Molecular Device) was used for data capture.

Cytosolic free $\mathrm{Zn}^{2+}$ measurements: Acquisitions were performed 24 hours after transfection using an Olympus IX-70 wide-field microscope with a 40x/1.35NA oil immersion objective and a zyla sCMOS camera (Andor Technology, Belfast, UK) controlled by Micromanager software. Excitation was provided at $433 \mathrm{~nm}$ using a monochromator (Polychrome IV, Till Photonics, Munich, Germany). Emitted light was split and filtered with a Dual-View beam splitter (Photometrics, Tucson, Az, USA) equipped with a 505dcxn dichroic mirror and two emission filters (Chroma Technology, Bellows Falls, VT, USA - D470/24 for cerulean and D535/30 for citrine). Cells were 660 perfused for 4 minutes with KREBS buffer $\left(140 \mathrm{mM} \mathrm{NaCl}, 3.6 \mathrm{mM} \mathrm{KCl}, 0.5 \mathrm{mM} \mathrm{NaH}_{2} \mathrm{PO}_{4}, 0.2\right.$ $661 \mathrm{mM} \mathrm{MgSO}_{4}, 1.5 \mathrm{mM} \mathrm{CaCl}_{2}, 10 \mathrm{mM}$ HEPES, $25 \mathrm{mM} \mathrm{NaHCO}_{3}$ ) without additives, next the buffer 662 was changed to KREBS buffer containing $50 \mu \mathrm{M} N, \mathrm{~N}_{2} \mathrm{~N}^{\prime}, \mathrm{N}^{\prime}$-tetrakis(2-

663 pyridylmethyl)ethylenediamine (TPEN, Sigma) for 5 minutes, followed by perifusion with KREBS 664 buffer containing $100 \mu \mathrm{M} \mathrm{ZnCl}_{2}$ and $5 \mu \mathrm{M}$ of the $\mathrm{Zn}^{2+}$-specific ionophore 2-mercaptopyridine $\mathrm{N}$ 665 oxide (Pyrithione, Sigma). Image analysis was performed using ImageJ software. Steady-state 
666 fluorescence intensity ratio of acceptor over donor was measured, followed by the determination of

667 the minimum and maximum ratios to calculate the free $\mathrm{Zn}^{2+}$ concentration using the following

668 formula: $\left[\mathrm{Zn}^{2+}\right]=\mathrm{Kd} \cdot((\mathrm{R}-\mathrm{Rmin}) /(\mathrm{Rmax}-\mathrm{R}))$, in which $\mathrm{Rmin}$ is the ratio in the $\mathrm{Zn}^{2+}$ depleted 669 state, after addition of $50 \mu \mathrm{M}$ TPEN, and Rmax was obtained upon $\mathrm{Zn}^{2+}$ saturation with $100 \mu \mathrm{M}$ $670 \mathrm{ZnCl}_{2}$ in the presence of $5 \mu \mathrm{M}$ pyrithione.

\section{Human Pancreatic islets}

672 Experiments on primary human pancreatic islets were independently performed in two places 1)

673 Oxford and 2) Lund university diabetes center (LUDC)

674 Human pancreatic islets from Oxford: Human pancreatic islets were isolated from deceased 675 donors under ethical approval obtained from the human research ethics committees in Oxford 676 (REC: 09/H0605/2, NRES committee South Central-Oxford B). All donors gave informed research consent as part of the national organ donation program. Islets were obtained from the Diabetes Research \& Wellness Foundation Human Islet Isolation Facility, OCDEM, University of Oxford. All methods and protocols using human pancreatic islets were performed in accordance with the relevant guidelines and regulations in the UK (Human Tissue Authority, HTA). Expression data for 681 SLC30A8 estimated by RNA sequencing as described previously ${ }^{57}$. For in vitro insulin secretion, 682 islets were pre-incubated in Krebs-Ringer buffer (KRB) containing $2 \mathrm{mg} / \mathrm{mL}$ BSA and $1 \mathrm{mM}$ 683 glucose for 1 hour at $37^{\circ} \mathrm{C}$, followed by 1-hour stimulation in KRB supplemented with $6 \mathrm{mM}$ 684 glucose. Insulin content of the supernatant was determined by radioimmunoassay (Millipore UK 685 Ltd, Livingstone, UK) as described previously ${ }^{58}$.

Human pancreatic islets from LUDC: Human pancreatic islets were obtained from the Human 
approved by the ethics committee at Lund University (Malmö, Sweden, permit number 2011263).

Islet preparation for cadaver donors, their purity check and counting procedure have been described previously ${ }^{61}$. Static in vitro insulin secretion assay from 91 islets (non-diabetic individuals) was performed as described previously ${ }^{61,62}$. Briefly, six batches of 12 islets per donor were incubated for 1 hour at $37^{\circ} \mathrm{C}$ in Krebs Ringer bicarbonate (KRB) buffer in presence of $1 \mathrm{mM}$ or $16.7 \mathrm{mM}$ glucose, as well as $1 \mathrm{mM}$ or $16.7 \mathrm{mM}$ glucose together with $70 \mathrm{mM} \mathrm{KCl}$. Insulin concentrations in the extracts was measured using a radioimmunoassay kit (Euro-Diagnostica, Malmö, Sweden). The Association of p.Trp325Arg genotype with expression of SLC30A8 and other genes involved in insulin production and processing ${ }^{22}$ was performed using RNA sequencing from islets of 140 nondiabetic individuals as described previously ${ }^{59,60}$. Briefly, RNA sequencing of islets was done using

700 a HiSeq 2000 system (Illumina) for an average depth of 32.4 million paired-end reads $(2 \times 100$ base 701 pairs) ${ }^{59,60}$. RNA sequencing reads were aligned to hg19 using STAR (Spliced Transcripts Alignment to Reference) ${ }^{51}$. Genome annotations were obtained from the GENCODE (Encyclopedia of Genes and Gene Variants) v20 22 program and read counting was done using featureCounts ${ }^{53}$. Read counts were normalized to total reads (counts per million) and additionally across-samples normalization was done using TMM method ${ }^{55}$. Association analysis (so called eQTL) was performed on inverse normalized expression values using linear regression adjusted for age, sex and islets purity.

\section{Statistics}

709 Detail information regarding statistical tests used for each sub-study has been provided in their 710 respective method section or with figure legends.

\section{Data availability}




\section{References}

1. Chabosseau, P., \& Rutter, G.A. Zinc and diabetes. Arch Biochem Biophys 611, 79-85 (2016).

2. Chimienti, F., Devergnas, S., Favier, A., \& Seve, M. Identification and cloning of a beta-cell-specific zinc transporter, ZnT-8, localized into insulin secretory granules. Diabetes 53, 2330-7 (2004).

3. Flannick, J. et al. Loss-of-function mutations in SLC30A8 protect against type 2 diabetes. Nat Genet 46, 357-63 (2014).

4. Flannick, J. et al. Genetic discovery and translational decision support from exome sequencing of 20,791 type 2 diabetes cases and 24,440 controls from five ancestries bioRxiv (2018).

5. Parsons, D.S., Hogstrand, C., \& Maret, W. The C-terminal cytosolic domain of the human zinc transporter ZnT8 and its diabetes risk variant. FEBS J. 285, 1237-1250 (2018).

6. Sladek, R. et al. A genome-wide association study identifies novel risk loci for type 2 diabetes. Nature $\mathbf{4 4 5}, 881-5$ (2007).

7. Lemaire, K. et al. Insulin crystallization depends on zinc transporter ZnT8 expression, but is not required for normal glucose homeostasis in mice. Proc Natl Acad Sci U S A 106, 14872-7 (2009).

8. Pound, L.D. et al. Deletion of the mouse Slc30a8 gene encoding zinc transporter-8 results in impaired insulin secretion. Biochem J 421, 371-6 (2009).

9. Wijesekara, N. et al. Beta cell-specific Znt8 deletion in mice causes marked defects in insulin processing, crystallisation and secretion. Diabetologia 53, 1656-68 (2010).

10. Mitchell, R.K. et al. Molecular Genetic Regulation of Slc30a8/ZnT8 Reveals a Positive Association with Glucose Tolerance. Mol Endocrinol. 30, 77-91 (2016).

11. Kleiner, S. et al. Mice harboring the human SLC30A8 R138X loss-of-function mutation have increased insulin secretory capacity. Proc Natl Acad Sci 115(32), E7642-E7649 (2018).

12. Groop, L. et al. Metabolic consequences of a family history of NIDDM (the Botnia study): evidence for sexspecific parental effects. Diabetes 45, 1585-93 (1996).

13. Tamaki, M. et al. The diabetes-susceptible gene SLC30A8/ZnT8 regulates hepatic insulin clearance. J Clin Invest 123, 4513-24 (2013).

14. Rezania, A. et al. Reversal of diabetes with insulin-producing cells derived in vitro from human pluripotent stem cells. Nat Biotechnol 32, 1121-33 (2014).

15. Miyaoka, Y., Chan, A.H., \& Conklin, B.R. Using Digital Polymerase Chain Reaction to Detect Single-Nucleotide Substitutions Induced by Genome Editing. Cold Spring Harb Protoc (2016).

16. Scharfmann, R. et al. Development of a conditionally immortalized human pancreatic $\beta$ cell line. J Clin Invest 124, 2087-98 (2014).

17. Hastoy, B. et al. Electrophysiological properties of human $\beta$-cell lines EndoC- $\beta \mathrm{H} 1$ and $-\beta \mathrm{H} 2$ conform with human $\beta$-cells. BioRxiv (2017).

18. Braun, M. et al. Voltage-gated ion channels in human pancreatic beta-cells: electrophysiological characterization and role in insulin secretion. Diabetes 57, 1618-28 (2008).

19. Srinivasan, S., Bernal-Mizrachi, E., Ohsugi, M., \& Permutt, M.A. Glucose promotes pancreatic islet beta-cell survival through a PI 3-kinase/Akt-signaling pathway. Am J Physiol Endocrinol Metab 283, E784-93 (2002).

20. Nicolson, T.J. et al. Insulin storage and glucose homeostasis in mice null for the granule zinc transporter ZnT8 and studies of the type 2 diabetes-associated variants. Diabetes $\mathbf{5 8}, 2070-83$ (2009).

21. Vinkenborg, J.L. et al. Genetically encoded FRET sensors to monitor intracellular Zn2+ homeostasis. Nat Methods 6, 737-40 (2009).

22. Zhou, Y. et al. TCF7L2 is a master regulator of insulin production and processing. Hum Mol Genet 23, 6419-31 (2014).

23. Kirchhoff, K. et al. Polymorphisms in the TCF7L2, CDKAL1 and SLC30A8 genes are associated with impaired proinsulin conversion. Diabetologia 51, 597-601 (2008). 
24. Jainandunsing, S. et al. A stable isotope method for in vivo assessment of human insulin synthesis and secretion. Acta Diabetol 53, 935-944 (2016).

25. Ivanova, A. et al. Age-dependent labeling and imaging of insulin secretory granules. Diabetes 62, 3687-96 (2013).

26. Gerber, P.A. et al. Hypoxia lowers SLC30A8/ZnT8 expression and free cytosolic Zn2+ in pancreatic beta cells. Diabetologia 57, 1635-44 (2014).

27. Wong, W.P. et al. Exploring the Association Between Demographics, SLC30A8 Genotype, and Human Islet Content of Zinc, Cadmium, Copper, Iron, Manganese and Nickel. Sci Rep 7 (1), 473 (2017).

28. Vergnano, A.M. et al. Zinc dynamics and action at excitatory synapses. Neuron 82, 1101-14 (2014).

29. Prost, A.L., Bloc, A., Hussy, N., Derand, R., \& Vivaudou, M. Zinc is both an intracellular and extracellular regulator of KATP channel function. J Physiol 559, 157-67 (2004).

30. Ferrer, R., Soria, B., Dawson, C.M., Atwater, I., \& Rojas, E. Effects of Zn2+ on glucose-induced electrical activity and insulin release from mouse pancreatic islets. Am J Physiol 246, C520-7 (1984).

31. Isomaa, B. et al., A family history of diabetes is associated with reduced physical fitness in the Prevalence, Prediction and Prevention of Diabetes (PPP)-Botnia study. Diabetologia 53, 1709-13 (2010).

32. Ahlqvist, E. et al. Novel subgroups of adult-onset diabetes and their association with outcomes: a data-driven cluster analysis of six variables. Lancet Diabetes Endocrinol 6, 361-369 (2018).

33. Lindgren, O. et al. Incretin hormone and insulin responses to oral versus intravenous lipid administration in humans. J Clin Endocrinol Metab 96, 2519-24 (2011).

34. Sluiter, W.J., Erkelens, D.W., Reitsma, W.D. \& Doorenbos, H. Glucose tolerance and insulin release, a mathematical approach I. Assay of the beta-cell response after oral glucose loading. Diabetes 25, 241-4 (1976).

35. Mohandas, C. et al. Ethnic differences in insulin secretory function between black African and white European men with early type 2 diabetes. Diabetes Obes Metab 20, 1678-1687 (2018).

36. Navalesi, R., Pilo, A. \& Ferrannini, E. Kinetic analysis of plasma insulin disappearance in nonketotic diabetic patients and in normal subjects. A tracer study with 125I-insulin. J Clin Invest 61, 197-208 (1978).

37. Delaneau, O., Zagury, J.F. \& Marchini, J. Improved whole-chromosome phasing for disease and population genetic studies. Nat Methods 10 (1), 5-6 (2013).

38. Flannick, J. et al. Sequence data and association statistics from 12,940 type 2 diabetes cases and controls. Sci Data 4, 170179 (2017).

39. Howie, B., Fuchsberger, C., Stephens, M., Marchini, J. \& Abecasis G.R. Fast and accurate genotype imputation in genome-wide association studies through pre-phasing. Nat Genet $\mathbf{4 4}, 955-9$ (2012)

40. Abecasis, G.R., Cardon, L.R., \& Cookson, W.O. A general test of association for quantitative traits in nuclear families. Am J Hum Genet 66, 279-92 (2000).

41. Yang, J., Lee, S.H., Goddard, M.E. \& Visscher, P.M. GCTA: a tool for genome-wide complex trait analysis. Am J Hum Genet 88, 76-82 (2011).

42. Bonetti, S. et al. Variants of GCKR affect both $\beta$-cell and kidney function in patients with newly diagnosed type 2 diabetes: the Verona newly diagnosed type 2 diabetes study 2. Diabetes Care 34, 1205-10 (2011).

43. van de Bunt, M. et al, Insights into islet development and biology through characterization of a human iPSCderived endocrine pancreas model. Islets 8, 83-95 (2016).

44. Cong, L. et al. Multiplex genome engineering using CRISPR/Cas systems. Science 339, 819-23 (2013).

45. Krentz, N.A.J. et al. Phosphorylation of NEUROG3 Links Endocrine Differentiation to the Cell Cycle in Pancreatic Progenitors. Dev Cell 41, 129-142.e6 (2017).

46. Perez-Alcantara, M. et al. Patterns of differential gene expression in a cellular model of human islet development, and relationship to type 2 diabetes predisposition. Diabetologia 61, 1614-1622 (2018).

47. Harries, L.W., Hattersley, A.T. \& Ellard S. Messenger RNA transcripts of the hepatocyte nuclear factor-1alpha gene containing premature termination codons are subject to nonsense-mediated decay. Diabetes 53, 500-4 (2004).

48. Ravassard, P. et al. A genetically engineered human pancreatic $\beta$ cell line exhibiting glucose-inducible insulin secretion. J Clin Invest 121, 3589-97 (2011).

49. Chandra, V. et al. RFX6 regulates insulin secretion by modulating Ca2+ homeostasis in human $\beta$ cells. Cell Rep 9, 2206-18 (2014).

50. Thomsen, S.K. et al. Systematic Functional Characterization of Candidate Causal Genes for Type 2 Diabetes Risk Variants. Diabetes 65, 3805-3811 (2016).

51. Dobin, A. et al. STAR: ultrafast universal RNA-seq aligner. Bioinformatics 29, 15-21 (2013).

52. Harrow, J. et al. GENCODE: the reference human genome annotation for The ENCODE Project. Genome Res. 22, 1760-74 (2012).

53. Liao, Y., Smyth, G.K. \& Shi, W. featureCounts: an efficient general purpose program for assigning sequence reads to genomic features. Bioinformatics 30, 923-30 (2014).

54. Robinson, M.D., McCarthy, D.J. \& Smyth G.K. "edgeR: a Bioconductor package for differential expression analysis of digital gene expression data." Bioinformatics, 26, 139-140 (2010). 
55. Robinson, M.D. \& Oshlack, A. A scaling normalization method for differential expression analysis of RNA-seq data. Genome Biol. 11, R25 (2010).

56. Asfari, M. et al. Establishment of 2-mercaptoethanol-dependent differentiated insulin-secreting cell lines. Endocrinology 130, 167-78 (1992).

57. van de Bunt, M. et al. Transcript Expression Data from Human Islets Links Regulatory Signals from GenomeWide Association Studies for Type 2 Diabetes and Glycemic Traits to Their Downstream Effectors. PLoS Genet. 11(12), e1005694 (2015).

58. Ramracheya, R. et al. Membrane potential-dependent inactivation of voltage-gated ion channels in alpha-cells inhibits glucagon secretion from human islets. Diabetes 59, 2198-208 (2010).

59. Ottosson-Laakso, E. et al. Glucose-Induced Changes in Gene Expression in Human Pancreatic Islets: Causes or Consequences of Chronic Hyperglycemia. Diabetes 66, 3013-3028 (2017).

60. Fadista, J. et al. Global genomic and transcriptomic analysis of human pancreatic islets reveals novel genes influencing glucose metabolism. Proc Natl Acad Sci U S A 111, 13924-9 (2014).

61. Rosengren, A.H. et al. Overexpression of alpha2A-adrenergic receptors contributes to type 2 diabetes. Science. 327, 217-20 (2010).

62. Taneera, J. et al. Identification of novel genes for glucose metabolism based upon expression pattern in human islets and effect on insulin secretion and glycemia. Hum Mol Genet 24, 1945-55 (2015).

\section{URLS}

GCTA, http://cnsgenomics.com/software/gcta; SHAPEIT,

http://mathgen.stats.ox.ac.uk/genetics_software/shapeit/shapeit.html, IMPUTE2,

http://mathgen.stats.ox.ac.uk/impute/impute_v2.html;

\section{Acknowledgements}

We thank the Botnia Study Group for recruiting and studying the participants, Jens Juul Holst for measuring GLP-1 concentrations, and Linda Boselli, PhD, for carrying out mathematical modelling of the OGTT studies. We thank Erqian Na for her help with the mouse immunohistochemistry and histology, and Catherine Green and the Chromosome Dynamics \& Genome Engineering Cores at the Wellcome Centre for Human Genetics for support with karotyping and genome editing (funded by the Welcome Trust grant 203141).The Botnia and The PPP-Botnia studies (L.G., T.T.) have been financially supported by grants from Folkhälsan Research Foundation, the Sigrid Juselius Foundation, The Academy of Finland (grants no. 263401, 267882, 312063 to LG, 312072 to TT), Nordic Center of Excellence in Disease Genetics, EU (EXGENESIS, EUFP7-MOSAIC FP7600914), Ollqvist Foundation, Swedish Cultural Foundation in Finland, Finnish Diabetes Research Foundation, Foundation for Life and Health in Finland, Signe and Ane Gyllenberg Foundation, Finnish Medical Society, Paavo Nurmi Foundation, Helsinki University Central Hospital Research Foundation, Perklén Foundation, Närpes Health Care Foundation and Ahokas Foundation, as well as by the Ministry of Education in Finland, Municipal Heath Care Center and Hospital in Jakobstad and Health Care Centers in Vasa, Närpes and Korsholm. The work described in this paper has been supported with funding from collaborative agreements with Pfizer Inc., as well as with Regeneron Genetics Center LLC. J.L. was supported by Vinnova - Sweden's Innovation Agency (201501549), Swedish Diabetes Foundation, Albert Påhlsson Foundation, Hjelt Foundations, Crafoord Foundation, Royal Physiographic Society in Lund, Swedish Foundation for Strategic Research (IRC15-0067), Swedish Research council (2009-1039, Strategic research area Exodiab); E.A. by Crafoord Foundation, Påhlsson Foundation, Swedish Research Council (Dnr: 2017-02688); O.H. by Lund University Diabetes Center, ALF, Crafoord foundation, Novo Nordisk foundation, Magnus Bergvall foundation, Påhlsson foundation, Diabetes Wellness and Swedish Diabetes Research Foundation; R.C.B. by Italian Ministry of University and Research (PRIN 2015373Z39_004) and University of Parma Research Funds; G.R. by a Wellcome Trust Senior Investigator Award (WT098424AIA), MRC Programme grants (MR/R022259/1, MR/J0003042/1, MR/L020149/1) and Experimental Challenge Grant (DIVA, MR/L02036X/1), MRC (MR/N00275X/1), Diabetes UK (BDA/11/0004210, BDA/15/0005275, BDA 16/0005485) and Imperial Confidence in Concept (ICiC) grants, and a Royal Society Wolfson Research Merit Award. ALG is a Wellcome Trust 
Senior Fellow in Basic Biomedical Science. M.I.M. and P.R. are Wellcome Senior Investigators. This work was funded in Oxford by the Wellcome Trust (095101 [ALG], 200837 [A.L.G.], 098381 [M.I.M.], 106130 [A.L.G., M.I.M.], 203141 (A.L.G., B.D., M.I.M.], 203141 [M.I.M.], 090531 [P.R.]), Medical Research Council (MR/L020149/1) [M.I.M., A.L.G., P.R.], European Union Horizon 2020 Programme (T2D Systems) [A.L.G.], and NIH (U01-DK105535; U01-DK085545) [M.I.M., A.L.G.]. The research was funded by the National Institute for Health Research (NIHR) Oxford Biomedical Research Centre (BRC) [A.L.G., M.I.M., P.R.]. The views expressed are those of the author(s) and not necessarily those of the NHS, the NIHR or the Department of Health.

\section{Author Contributions}

M.L., L.S., T.T. and L.G. conducted the human study; E.A., O.H., A.B. and J.F. analyzed the genotype data ; M.L., O.P.D., M.T., E.B., R.C.B, T.T. and L.G. analyzed the human data; B.H., N.L.B., S.K.T., M.vD.B., V.C., O.P.D., T.O. and A.L.G. characterized the Human beta-cell model; N.L.B., N.A.J.K., F.A., B.C., D.M., P.K., B.D., M.I.M. and A.L.G. characterized the human IPS cell derived model; U.K., R.P., O.P.D., B.H., A.J.P., I.S., R.R., I.A., P.R., M.I.M. and A.L.G. characterized the human islets; S.K., D.G. and J.G. characterized the Slc30a8 p.Arg138* mice; D.J., J.L., P.C., A.T., R.C., A-M.R., J.B. and G.R. characterized the rat insulinoma cell-line; M.I.M., A.L.G., T.T. and L.G. supervised the project; O.P.D., M.L., B.H., S.K., N.K., P.R., A.L.G., T.T., and L.G. wrote the manuscript; all authors revised the manuscript.

\section{Materials \& Correspondence}

Correspondence and requests for materials should be addressed to L.G. (leif.groop@med.lu.se) or A.L.G(anna.gloyn@drl.ox.ac.uk)

\section{Competing interests}

L.G. has received research funding from Pfizer Inc, Regeneron Pharmaceuticals, Eli Lilly and Astra Zeneca. N.L.B. and M.vD.B are now employees of Novo Nordisk, although all experimental work was carried out under employment at the University of Oxford. ALG has received honoraria from Novo Nordisk. MIM serves on advisory panels for Pfizer, Novo Nordisk, Zoe Global; has received honoraria from Pfizer, Novo Nordisk and Eli Lilly; has stock options in Zoe Global; has received research funding from Abbvie, Astra Zeneca, Boehringer Ingelheim, Eli Lilly, Janssen, Merck, Novo Nordisk, Pfizer, Roche, Sanofi Aventis, Servier, Takeda. 
bioRxiv preprint doi: https://doi.org/10.1101/436030; this version posted October 22, 2018 . The copyright holder for this preprint (which was not certified by peer review) is the author/funder, who has granted bioRxiv a license to display the preprint in perpetuity. It is made available under aCC-BY-NC-ND 4.0 International license.

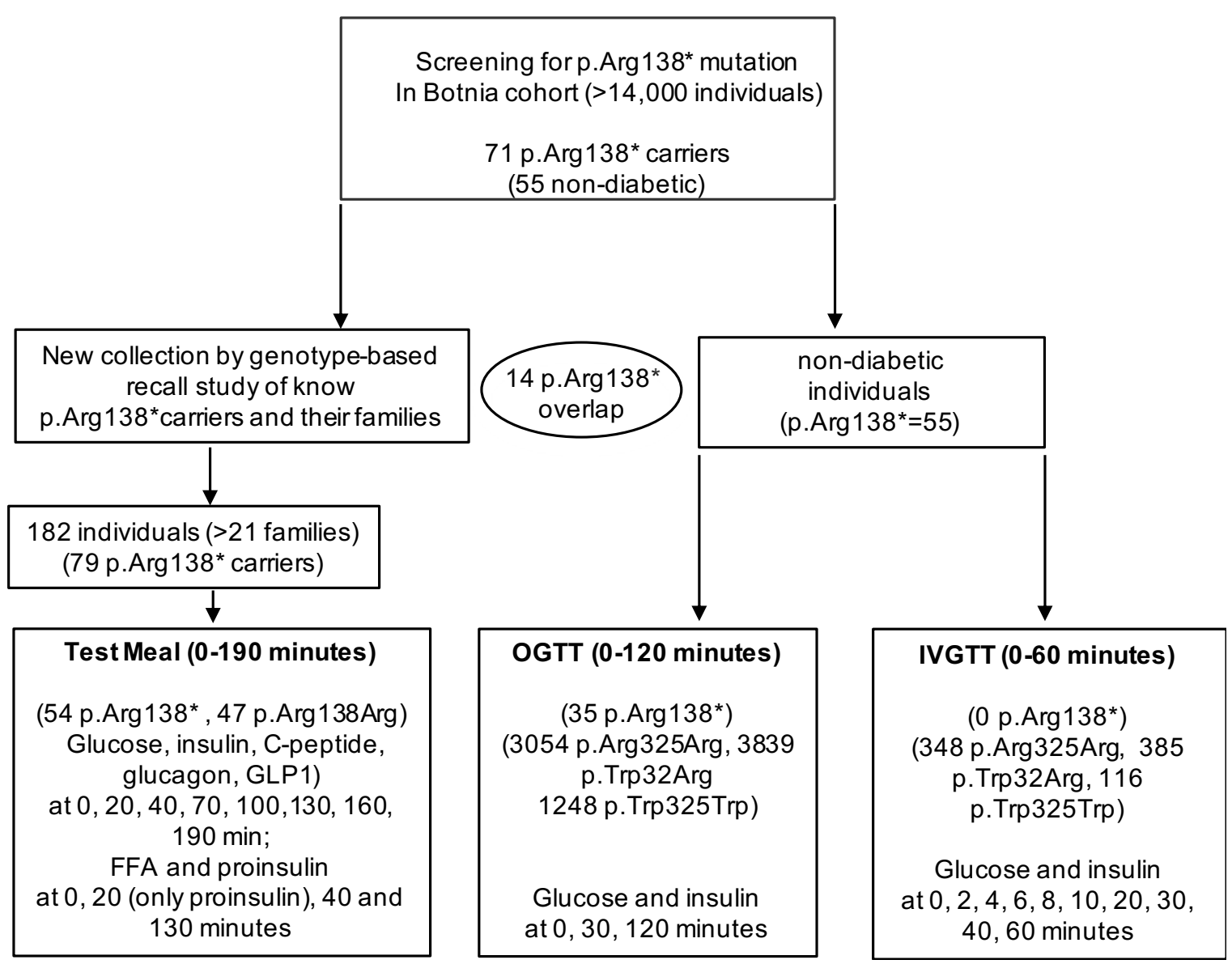

Fig. 1: A flow-chart of study design for human in vivo studies 

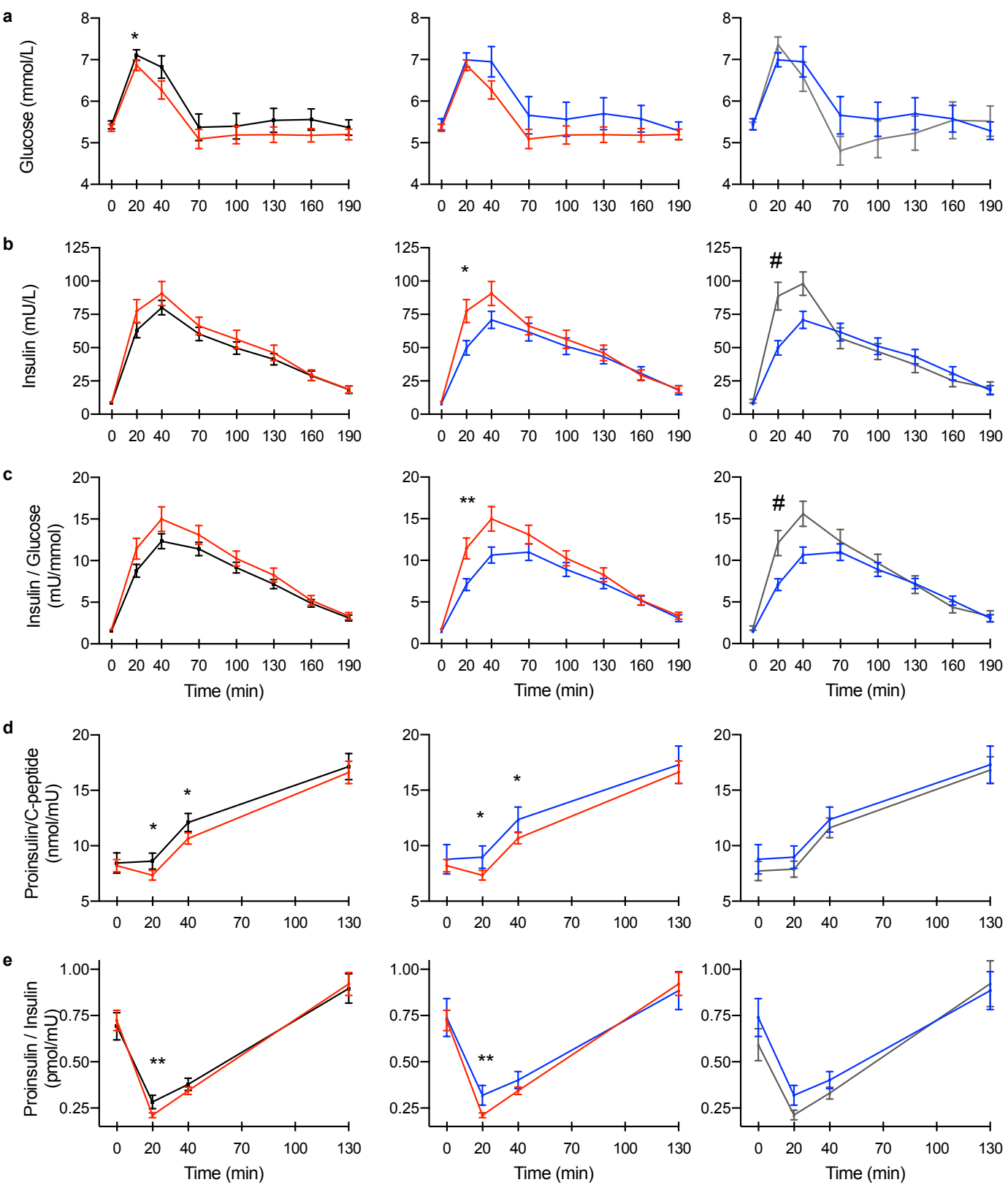

Fig. 2: SLC30A8-p.Arg138* enhances insulin secretion and proinsulin processing during test meal.

Association of SLC30A8 p.Arg 138* and p.Trp325Arg variants with a, plasma glucose b, serum insulin $\mathbf{c}$, insulin/glucose ratio d, proinsulin/C-peptide ratio and e, proinsulin/insulin ratio during test meal. Left panel: Carriers (red, $\mathrm{N}=54$ ) vs. non-carriers (black, N=47) of p.Arg138*. Middle panel: Carriers of p.Arg138* (red, N=54) vs Arg138Arg having the common risk variant p.Arg325 (blue, N=31). Right panel: Carriers of p.Trp325Trp (grey, N=16) vs. p.Arg325 (blue, $\mathrm{N}=31$ ). Data are Mean \pm SEM. P-values were calculated by family-based association $(*)$ or linear regression (\#) (adjusted for age, sex, BMI and p.Trp325Arg variant status for the middle pane, Methods): */\#, p $<0.05$, 

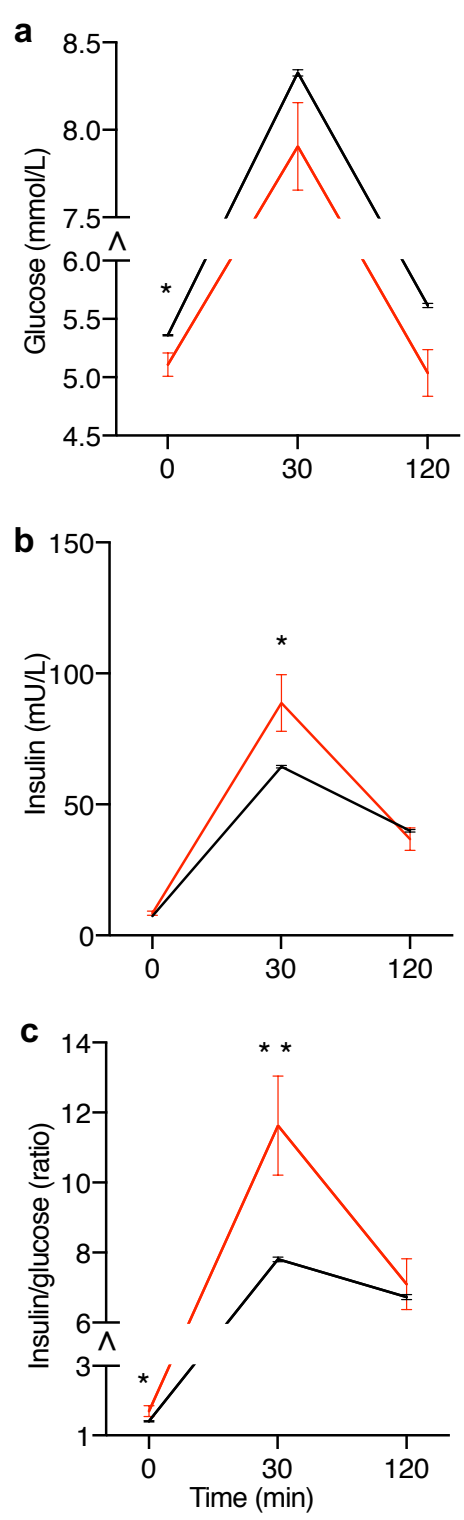
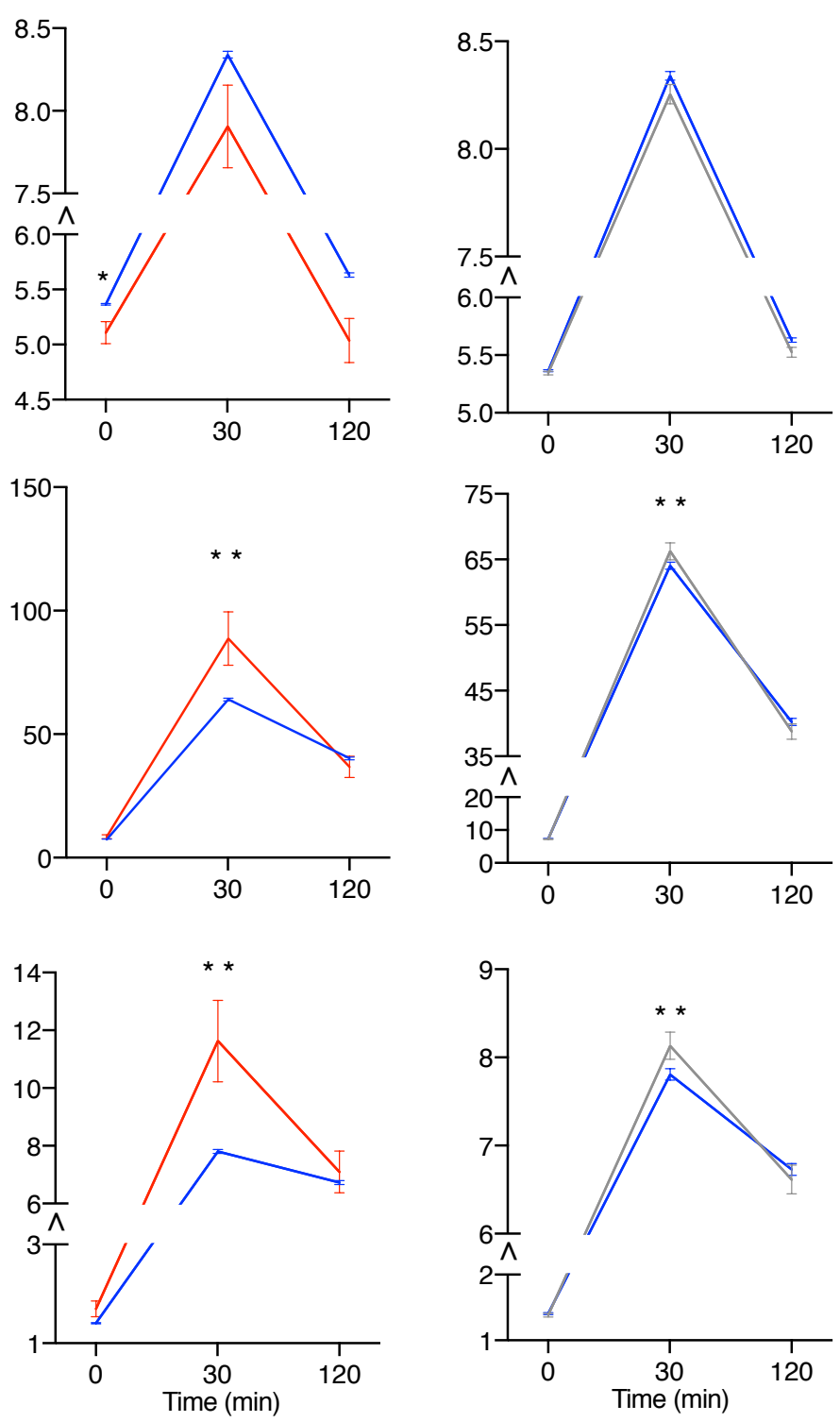

Fig. 3: SLC30A8 p.Arg138* and p.Trp325 enhance insulin secretion during OGTT.

Association of $S L C 30 A 8$ p.Arg $138^{*}$ and p.Trp325Arg with a, plasma glucose $\mathbf{b}$, serum insulin $\mathbf{c}$, insulin/glucose ratio during an oral glucose tolerance test (OGTT). Left panel: Carriers (red, N=35) vs. non-carriers (black, N=7954-8141) of p.Arg138*. Middle panel: Carriers of p.Arg138* (red, N=35) vs. p.Arg138Arg having the common risk variant p.Arg325 (blue, $\mathrm{N}=6728-6893$ ). Right panel: Carriers of p.Trp325Trp (grey N=1226-1248) vs. p.Arg325 (blue, $\mathrm{N}=6728$-6893). Data are shown as Mean \pm SEM. P-values (mixed model, Methods) using additive effect: $*<0.05, * *<$ 0.01 . Y-axis: note truncation $(\wedge)$ and different scale in the right panel. 

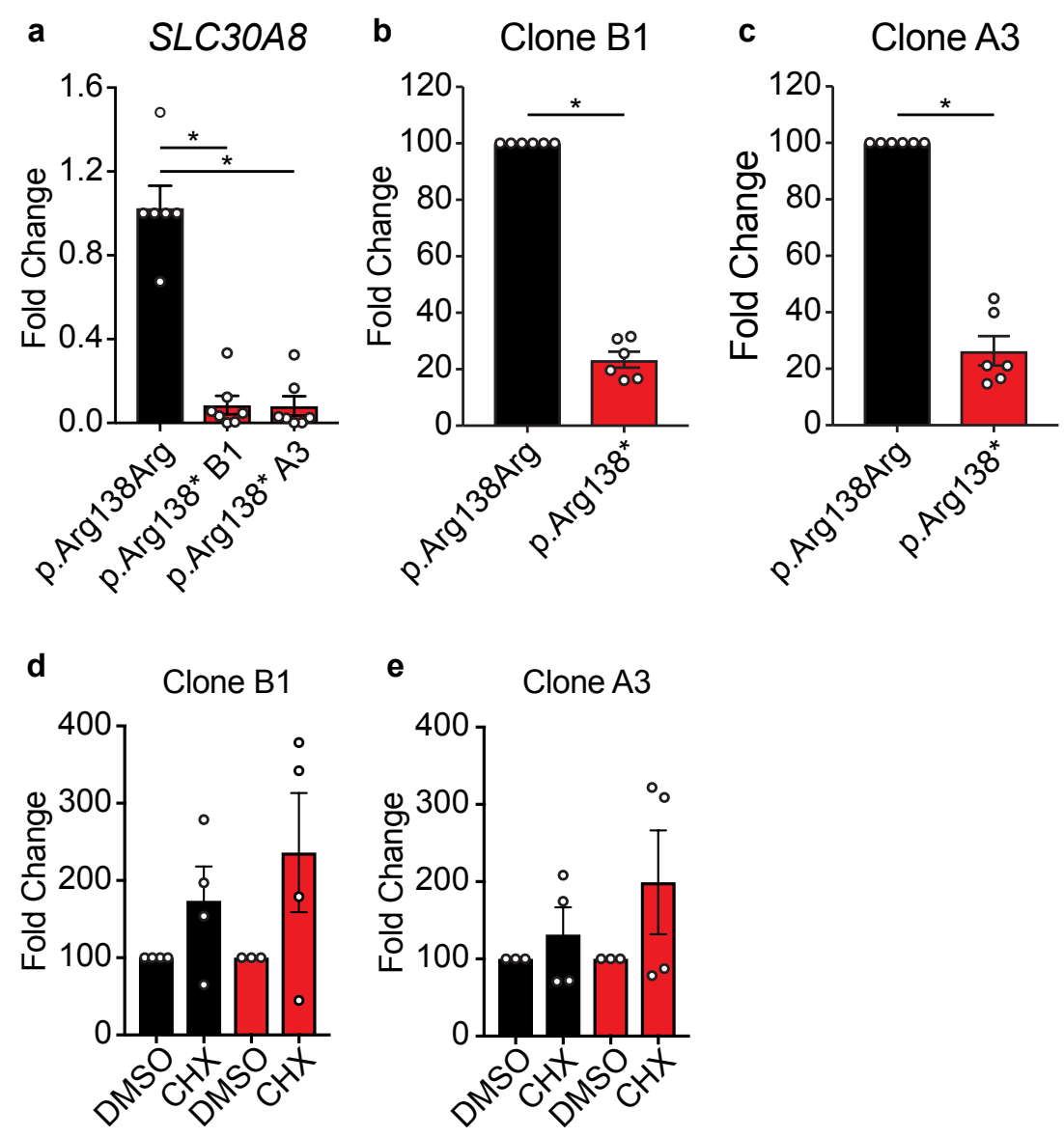

Fig. 4: Beta like cells derived from SLC30A8-p.Arg138* iPSCs display haploinsufficiency of SLC30A8.

a, SLC30A8 expression in cells heterozygous for SLC30A8-p.Arg138*. Data normalized to TBP gene are expressed as fold change relative to $\mathrm{p}$.Arg138Arg control ( $\mathrm{n}=6-7$ wells from two differentiations). Allele-specific expression (ASE) of p.Arg138Arg (black bar) and p.Arg138* (red bar) in b, clone B1 or c, clone A3 derived cells. Allele-specific expression of p.Arg138Arg (black bar) and p.Arg138* (red bar) in d, clone B1 and e, clone A3 derived cells treated with DMSO (Dimethyl sulfoxide) or cycloheximide (CHX) for four hours. ASE data (Mean \pm SEM) were determined by Digital Droplet PCR and presented as fold change relative to p.Arg138Arg transcript (b, $\mathbf{c}, \mathrm{n}=6$ wells from two differentiations) or to DMSO control (d-e, $\mathrm{n}=3-4$ wells from two differentiation). ${ }^{*} \mathrm{P}<0.05$ (Kruskal-Wallis test for multiple comparisons or unequal variance t-test). 

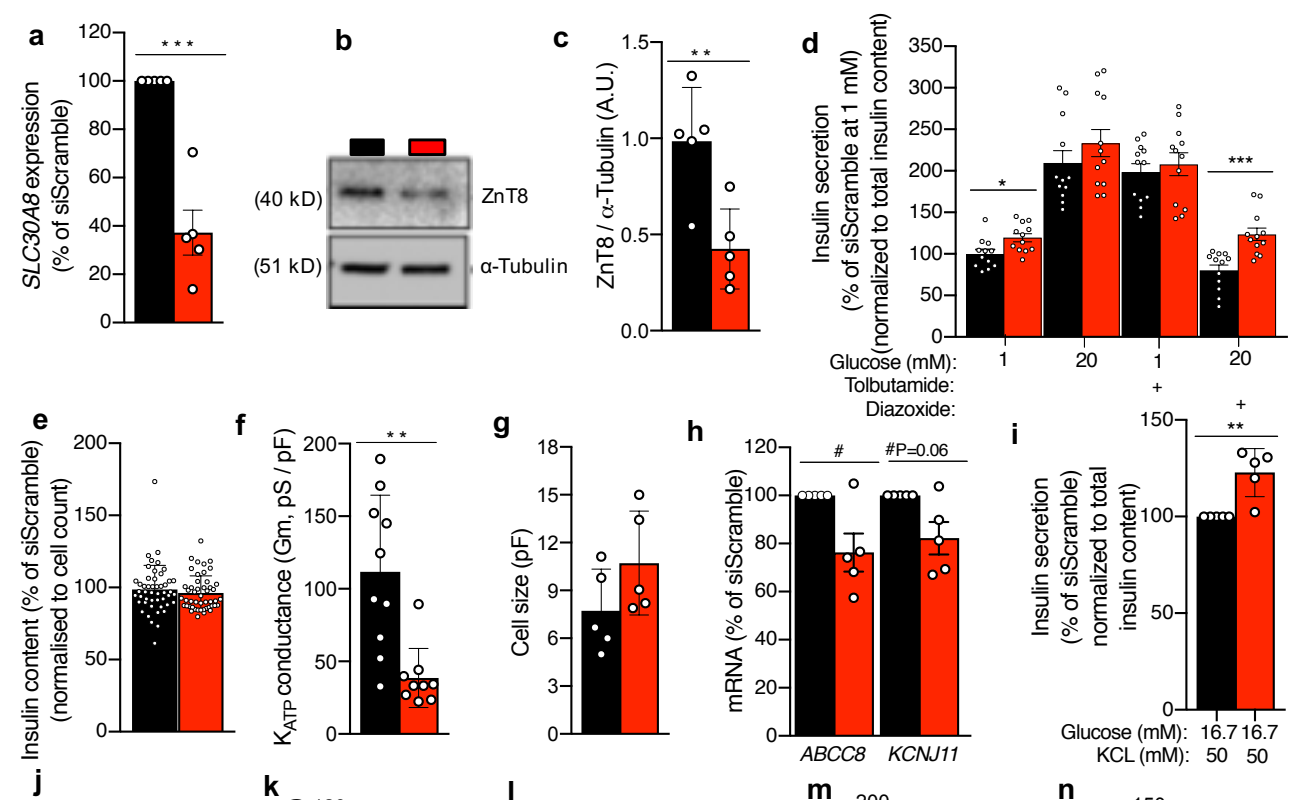

h Diazoxide:
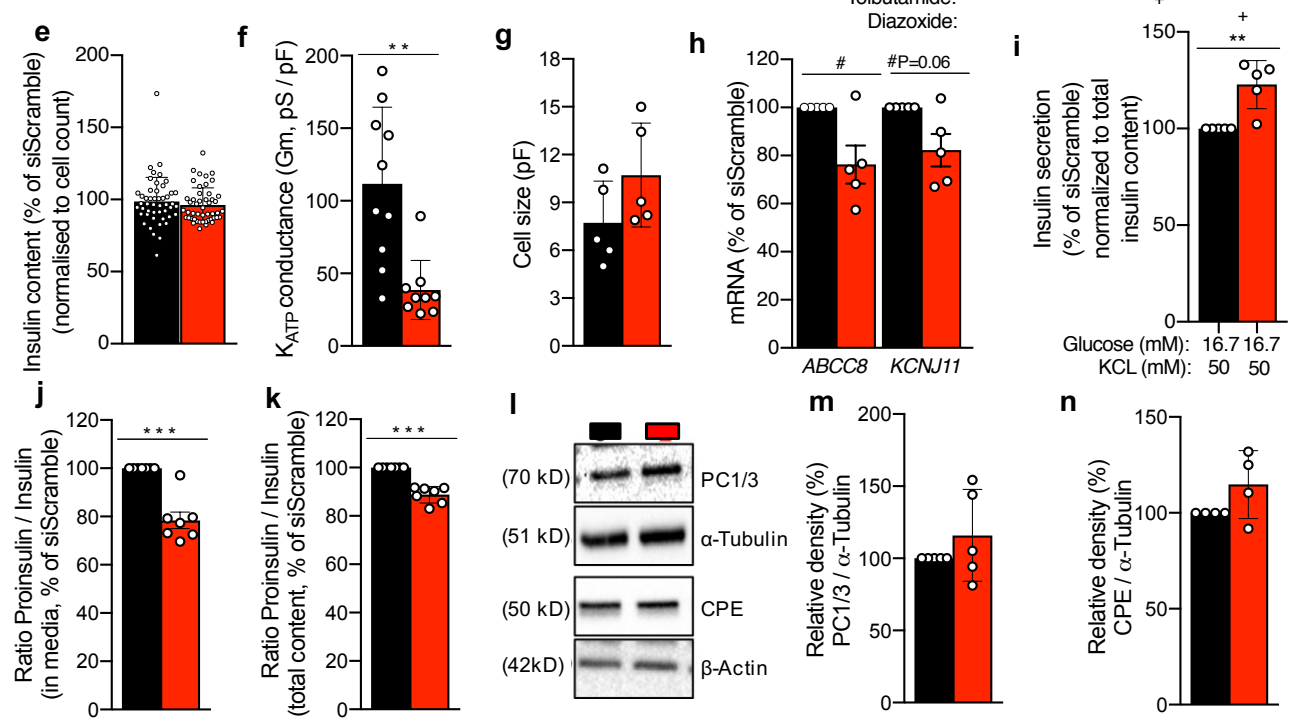

m 200
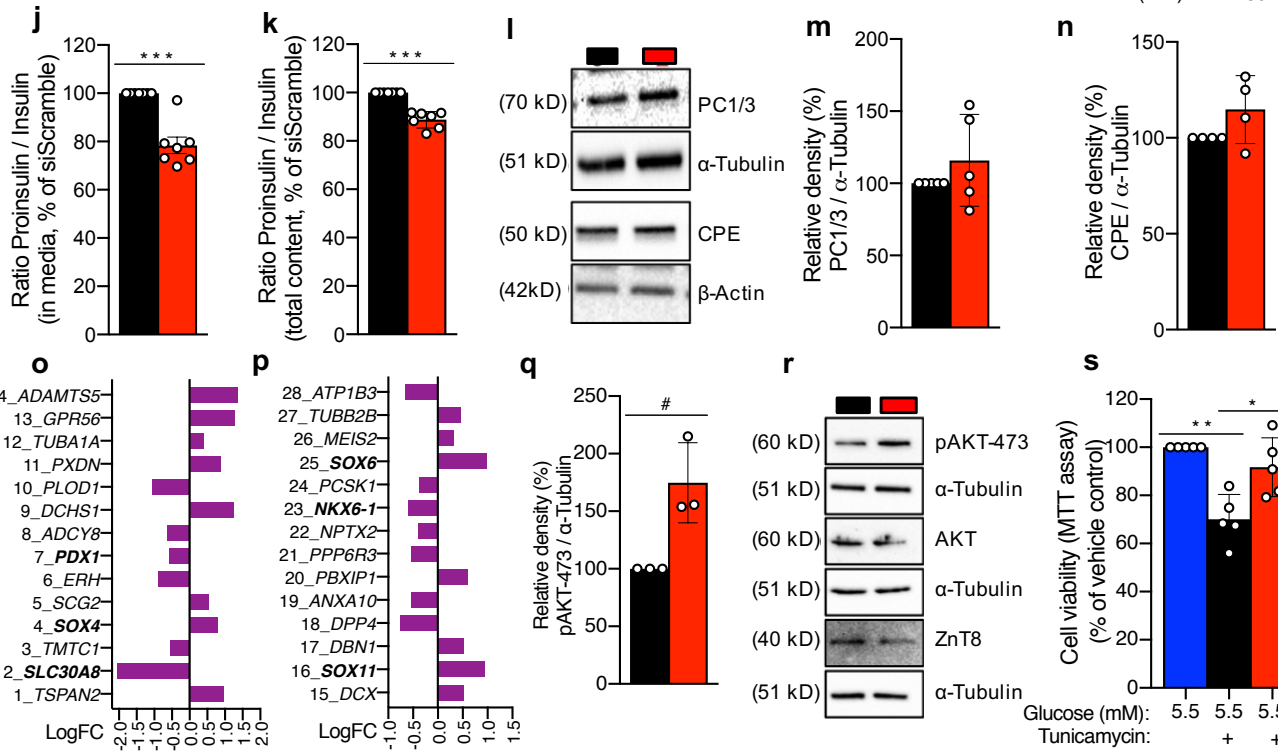

q
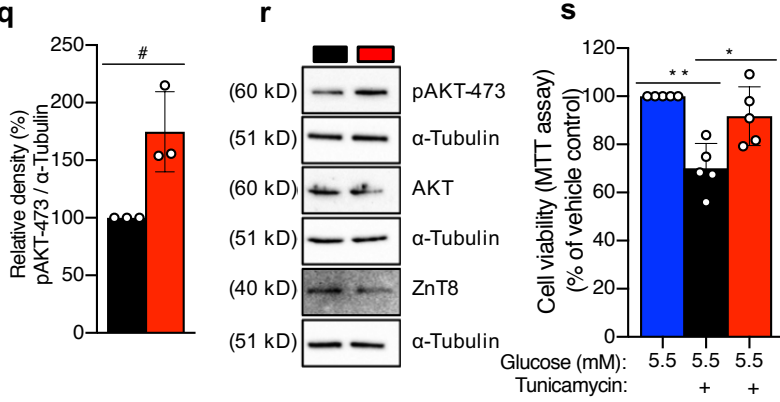

1060

1061

1062

1063

Fig. 5: SLC30A8 knock down leads to enhanced insulin secretion, proinsulin processing and cell viability in the human pancreatic EndoC- $\beta$ h1 cells.

a-c, Characterization of SLC30A8 knock down (KD) at the (a) mRNA and protein level (b-immunoblot, cdensitometry). d-i, Effect of KD on (d) insulin secretion stimulated by glucose and KATP channel regulators (as labelled), (e) insulin content, (f) KATP channel conductance (Gm), (g) cell size, (h) expression of KATP channel subunits, (i) insulin secretion stimulated by KCL and high glucose. $\mathbf{j}-\mathbf{n}$, Effect of KD on proinsulin processing estimated by (j-k) proinsulin/insulin ratio and proinsulin processing enzymes PC1/3 and CPE (l, immunoblot, $\mathbf{m}-\mathbf{n}$, densitometry). o-p, Effect of $\mathrm{KD}$ ( $\mathrm{n}=3$ vs. 3 ) on whole transcriptome (mRNAs) by next generation sequencing and depicting 28 top candidate genes ranked by increasing $\mathrm{p}$ values (1\% FDR corrected, $\mathrm{P} \leq 0.0002)$. q-s, Effect of KD on basal (5.5 mM glucose) AKT phosphorylation (q, densitometry, r, immunoblot; phospho-AKT-Ser473, total AKT) and cell viability under ER stress (s, MTT assay, $10 \mu \mathrm{g} / \mathrm{ml}$ tunicamycin, DMSO as vehicle control). Data are shown as Mean $\pm \mathrm{SEM}$ $(\mathrm{N}=3-10)$. P-values $\left({ }^{*}\right.$ Mann-Whitney test $/{ }^{*}$ Unpaired $\mathrm{t}$ test $): * / \# \mathrm{p} \leq 0.05,{ }^{* *} \mathrm{p}<0.01,{ }^{* * *} \mathrm{p}<0.001$. 
1073

1074

1075

1076

1077

1078

1079

1080

1081

1082

1083

1084

1085

1086

1087

1088

1089

1090

1091

1092

1093

1094

1095

1096

1097

1098 a

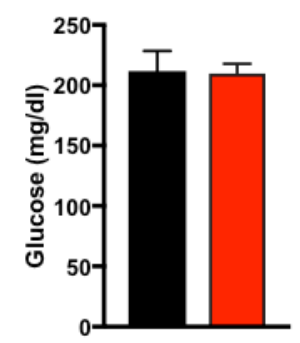

e

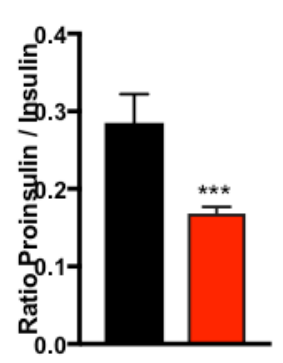

b

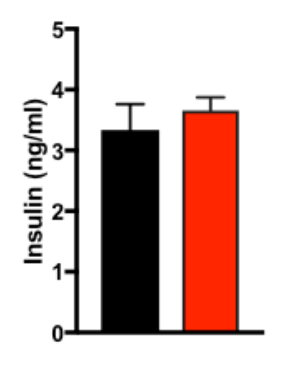

f

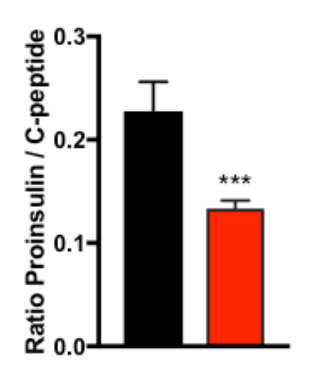

C

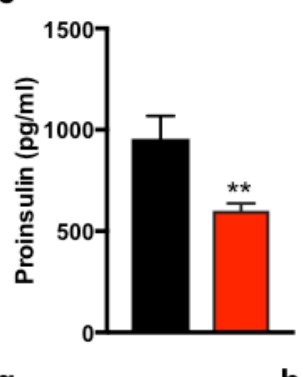

d WT

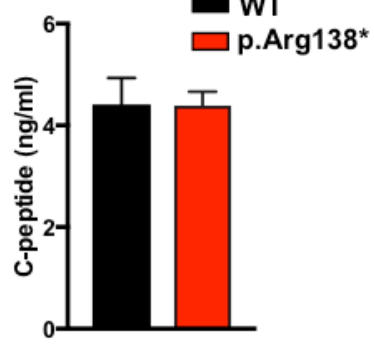

h

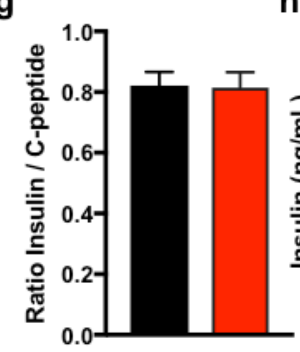

${ }^{80} 7 \rightarrow W T$

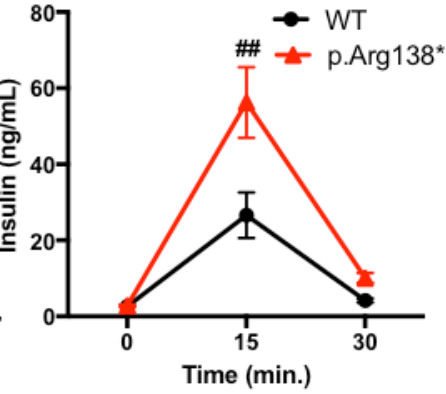

Fig. 6: Male p.Arg138* mice on high-fat diet show enhanced insulin secretion and proinsulin processing.

Circulating a, glucose $\mathbf{b}$, insulin $\mathbf{c}$, proinsulin $\mathbf{d}, \mathrm{C}$-peptide $\mathbf{e}$, proinsulin/insulin ratio f, proinsulin/C-peptide ratio and $\mathbf{g}$, insulin/C-peptide ratio in fasted WT and p.Arg138* mice (n= 10 WT, 17 p.Arg138*) after 20 weeks on HFD. h, Insulin response to oral glucose $(2 \mathrm{~g} / \mathrm{kg})$ exposure ( $=5 \mathrm{WT}, 11 \mathrm{p}$.Arg $\left.138^{*}\right)$ after 30 weeks on HFD. $\mathrm{p}^{* *}<0.01, \mathrm{p}^{* * *}<0.005$ using Students T test; $\mathrm{p}^{\# \#<0.01}$ using two-way Anova. 


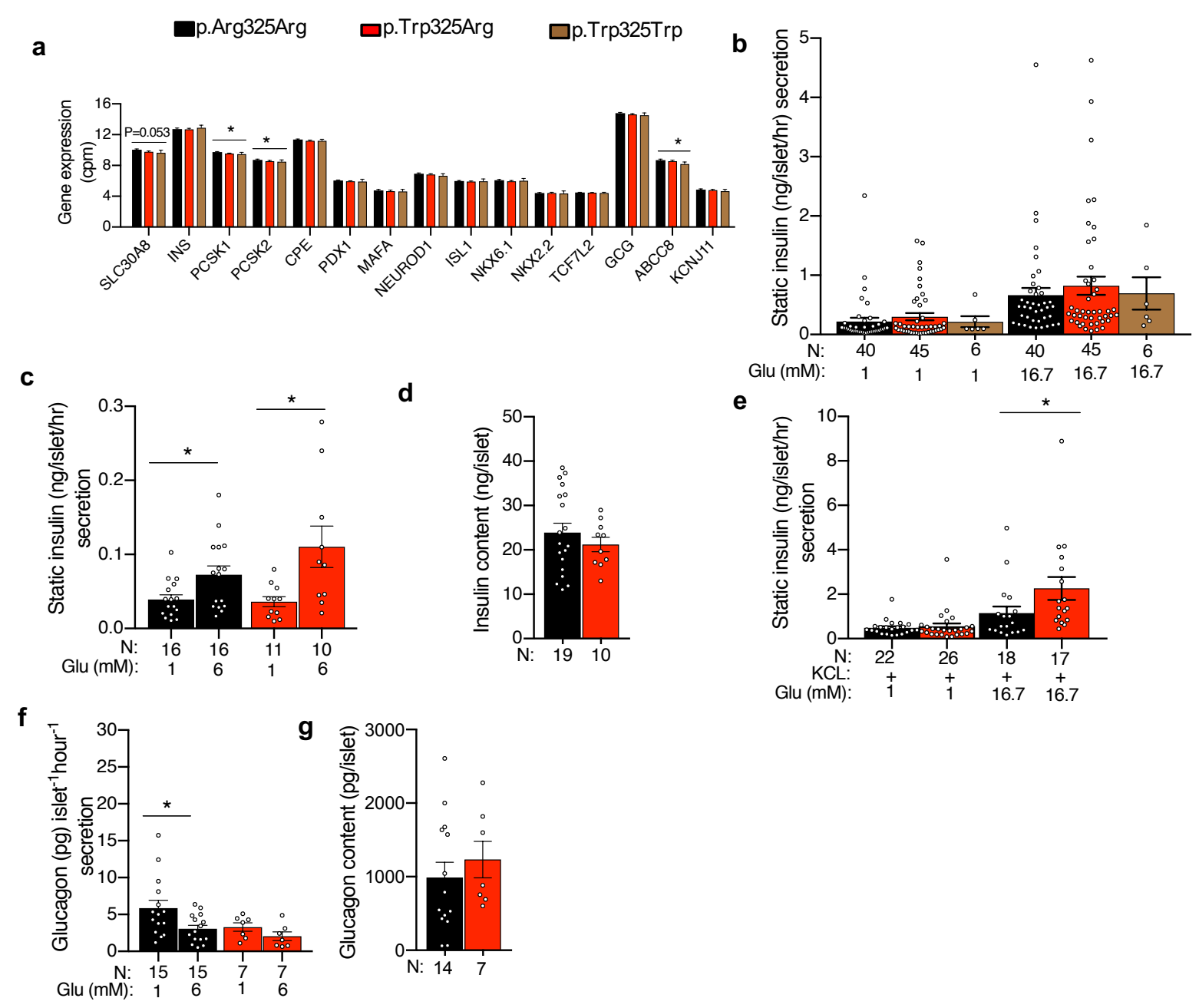

1101 Fig. 7: SLC30A8- p.Trp325 leads to enhanced insulin secretion in human islets.

1102 a, Effect of p.Trp325Arg genotype (p.Arg325Arg=66, p.Trp325Arg=63 and p.Trp325Trp=11) on expression of

1103 SLC30A8 and other genes involved in insulin production, secretion and processing. b. Effect of p.Trp325Arg genotype 1104 on static insulin secretion in presence of low and high glucose stimulatory conditions. c-d, Effect of p.Trp325Arg 1105 genotype on static insulin secretion in (c) low stimulatory conditions and their (d) insulin contents. e, Effect of 1106 p.Trp325Arg genotype on static insulin secretion in presence of low and high glucose and KCL. f, Static glucagon 1107 response to glucose and $\mathbf{g}$, glucagon content at basal glucose. Data are Mean \pm SEM; Glu- glucose. Analysis by linear 1108 regression or Mann-Whitney test (Methods); * $\mathrm{p}<0.05$. 